\title{
REVISTA DE ARQUITECTURA
}
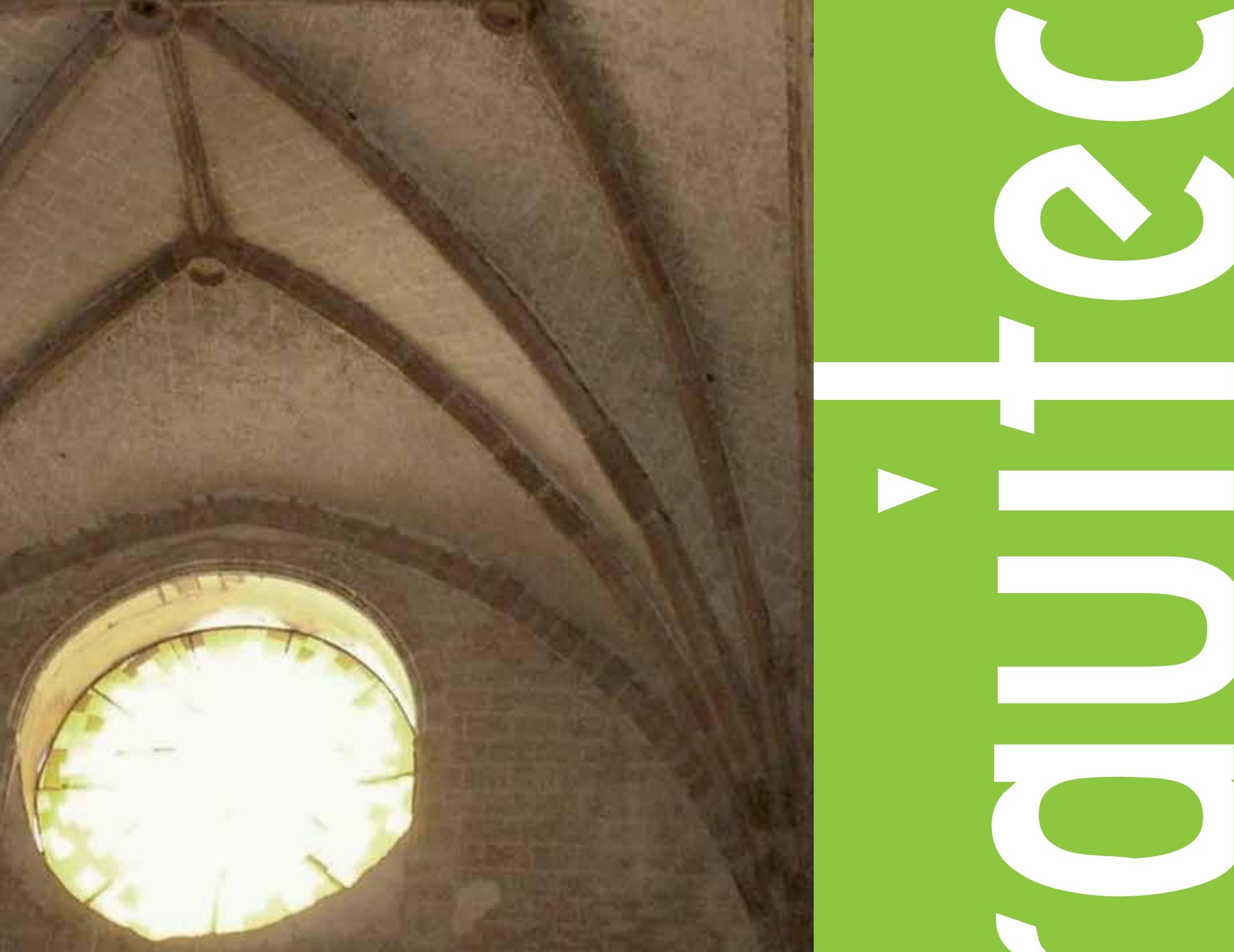

車 
La Revista de Arquitectura es una publicación seriada dirigida a la comunidad académica y profesional de las áreas afines a la disciplina (Arquitectura y Urbanismo), en donde se presentan resultados originales e inéditos de investigación. El primer número se publicó en 1999 y continúa con una periodicidad anual; es editada por la Facultad de Arquitectura de la Universidad Católica de Colombia. La revista se estructura en tres secciones correspondientes a las líneas de investigación aprobadas por la institución, a saber:

CULTURA Y ESPACIO URBANO. En esta sección se publican los artículos que se refieren a fenómenos sociales en relación con el espacio y el territorio urbano.

PROYECTO ARQUITECTÓNICO Y URBANO. Esta sección presenta artículos sobre el concepto de proyecto, entendido como elemento que define y orienta las condiciones proyectuales que devienen en los hechos arquitectónicos o urbanos, y la forma como estos se convierten en un proceso de investigación y de producción nuevo de conocimiento. También se presentan proyectos que sean resultados de investigación, que se validan a través de la ejecución y transformación en obra construida del proceso investigativo.

TECNOLOgíA, MEDIOAMBIENTE Y SOSTENIBILIDAD. En esta sección se presentan artículos acerca de sistemas estructurales, materiales y procesos constructivos, medioambiente y gestión, relacionados con el entorno social, cultural y ecológico.

\section{(A) Imagen base de la portada:}

Bóvedas del coro y de la nave del templo de Oaxtepec.

Foto: Natalia García, 2011

La Revista de Arquitectura recibe de manera permanente artículos, por lo cual no existen fechas de apertura y cierre de convocatorias.

El idioma principal es el español y como opcionales están definidos el inglés y el portugués; los textos pueden ser escritos y presentados en cualquiera de estos.

A El editor y los autores son responsables de los artículos aquí publicados.

Los autores son los responsables del material gráfico publicado.

Se autoriza la reproducción total o parcial de los artículos, siempre y cuando se haga la solicitud formal y se citen la fuente y el autor.
A Universidad Católica de Colombia (2012, enero-diciembre). Revista de Arquitectura, 14. 1-128. ISSN: 1657-0308

Especificaciones:

Formato: $\quad 34 \times 24 \mathrm{~cm}$

Papel: $\quad$ Mate $115 \mathrm{~g}$

Tintas: Negro y policromía

Periodicidad: Anual 


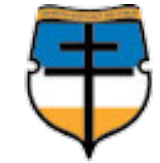

UNIVERSIDAD CATÓLICA de Colombia

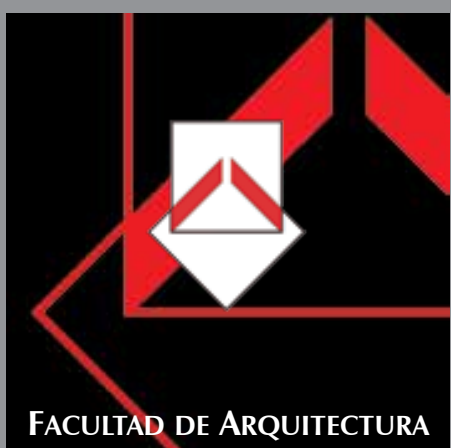

FACULTA
UNIVERSIDAD CATÓLICA

\section{DE COLOMBIA}

PRESIDENTE

Édgar Gómez Betancourt

VICEPRESIDENTE - RECTOR

Francisco José Gómez Ortiz

VICERRECTOR JURÍDICO Y DEL MEDIO

UNIVERSITARIO

Edwin de Jesús Horta Vásquez

VICERRECTOR ADMINISTRATIVO

Édgar Gómez Ortiz

DECANA ACADÉMICA

Irene Rodríguez Castillo

DIRECTORA DE INVESTIGACIONES

María Eugenia Guerrero Useda

DIRECTORA DE EDICIONES

Stella Valbuena García

\section{FACULTAD DE ARQUITECTURA}

DECANO

Werner Gómez Benítez

DIRECTOR DE DOCENCIA

Jorge Gutiérrez Martínez

DIRECTOR DE EXTENSIÓN

Carlos Beltrán Peinado

DIRECTOR DE INVESTIGACIÓN

Juan Carlos Pérgolis

DIRECTOR DE GESTIÓN DE CALIDAD

Augusto Forero La Rotta

COMITÉ ASESOR EXTERNO

FACULTAD DE ARQUITECTURA:

Alberto Miani Uribe

Octavio Moreno

Felipe Bernal Henao

Lorenzo Castro

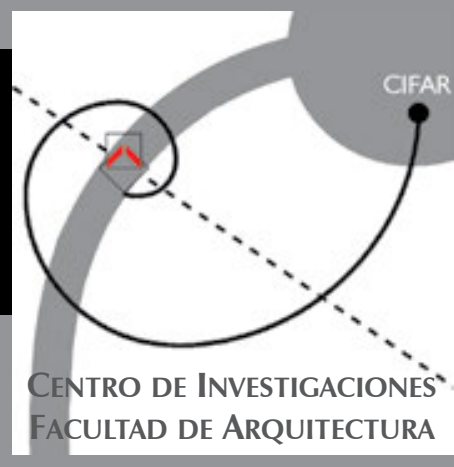

REVISTA ARBITRADA E INDEXADA

Publindex. Índice Bibliográfico Nacional IBN -

Redalyc. Red de Revistas Cientíícas de América Latina

y el Caribe, España y Portugal. Sistema de Información

Clase. Base de datos bibliográfica de revistas de

ciencias sociales y humanidades. Universidad

Autónoma México.

Ebsco. EBSCOhost Research Databases. Estados

Unidos.

Latindex. Sistema Regional de Información en Línea

para Revistas Científicas de América Latina, el Caribe,

España y Portugal (Directorio). México.

Dialnet. Fundación Dialnet - Biblioteca de la

Universidad de La Rioja. España.

Actualidad Iberoamericana. (Índice de Revistas) Centro

献

Arla. Asociación de revistas latinoamericanas de

arquitectura.

SUSCRIPCIONES, ADQUISICIONES Y

COMENTARIOS

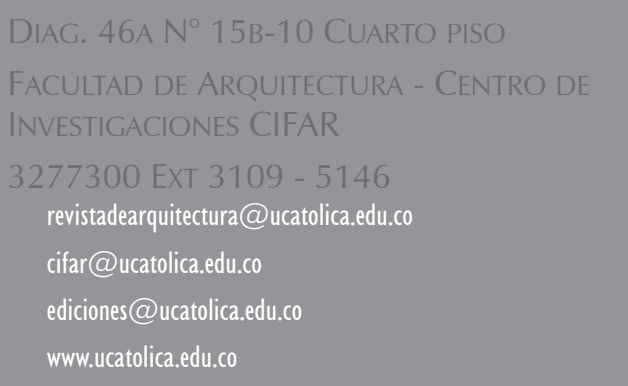

IMPRESIÓN:

ESCALA Taller Litográfico

Calle $30 \mathrm{~N}^{\circ}$ 17-52 - (057 I) 2320482

Diciembre de 2012

\section{REVISTA DE ARQUITECTURA}

DIRECTOR

Werner Gómez Benítez

EDITOR

César Andrés Eligio Triana

CONSEJO EDITORIAL

Werner Gómez Benítez

Jorge Gutiérrez Martínez

César Andrés Eligio Triana

Carlos Beltrán Peinado

Hernando Verdugo Reyes

IMAGEN \& DISEÑO

DISEÑO Y MONTAJE

Juanita Isaza - juanaisaza@gmail.com

TRADUCTOR TÉCNICO

Carlos Álvarez de la Roche

CORRECTORA DE ESTILO

María José Díaz Granados M.

PÁGINA WEB

Óscar Mauricio Pérez

DISTRIBUCIÓN Y CANJES

Claudia Álvarez Duquino
COMITÉ EDITORIAL

(A) Sonia Berjman, Ph.D.

ICOMOS, Buenos Aires, Argentina

Beatriz García Moreno, Ph.D.

Universidad Nacional de Colombia. Bogotá, Colombia

Juan Carlos Pérgolis, Msc.

Universidad Católica de Colombia. Bogotá, Colombia

René Julio Castillo, Msc. Ph.D. (Estudios)

Universidad del Rosario. Bogotá, Colombia

A Hugo Modragón López, Ph.D. Pontificia Universidad Católica de Chile. Santiago, Chile

Juan Pablo Duque Cañas, Ph.D. Universidad Nacional de Colombia. Bogotá, Colombia

Germán Darío Correal Pachón, Msc. Universidad Católica de Colombia. Bogotá, Colombia

(A) Luis Gabriel Gómez Azpeitia, Ph.D. Universidad de Colima. Colima, México

Luis Carlos Herrera Sosa, Ph.D. Universidad Autónoma de Ciudad Juárez, México

COMITÉ CIENTíFICO

Jorge Grané del Castillo, Msc. Universidad de Costa Rica. San José, Costa Rica

Javier Peinado Pontón, Msc. Pontificia Universidad Javeriana. Bogotá, Colombia

Jorge Alberto Villamizar Hernández Universidad Santo Tomás. Bucaramanga, Colombia

Augusto Forero La Rotta, Msc. Universidad Católica de Colombia. Bogotá, Colombia

Luis Álvaro Flórez Millán, Msc. Universidad Católica de Colombia. Bogotá, Colombia

Elvia Isabel Casas Matiz, Msc.

Universidad Católica de Colombia. Bogotá, Colombia 


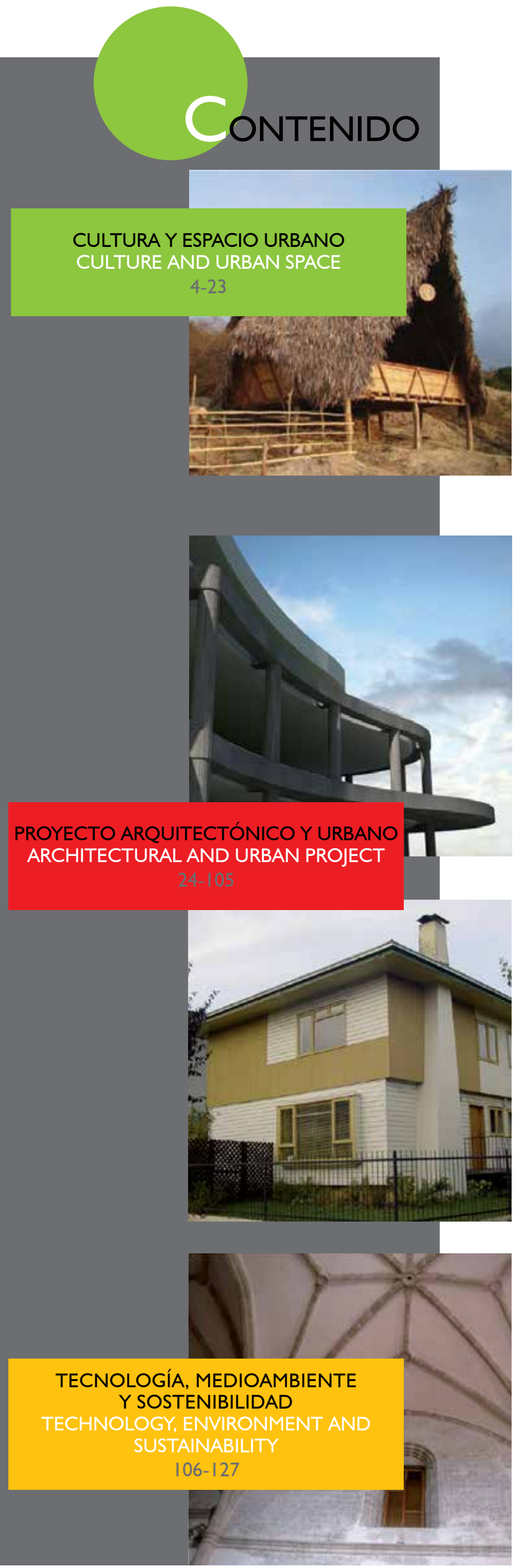

ARQUITECTURA PARTICIPATIVA:

LAS FORMAS DE LO ESENCIAL

WILLIAM GARCÍA R.

PÁG. 4

LA CIUDAD MODERNA,

LITERALMENTE HABLANDO

O CÓMO LEER LO QUE DICEN LOS ESCRITORES DE

FICCIÓN SOBRE LA ARQUITECTURA Y EL URBANISMO

MAURICIO MUÑOZ

UNA VENTANA PARA VER LA CIUDAD:

EL PARK WAY ( I 944-2000)

José ORLANDO JAIMES NIETO

PÁG. 20

CARÁCTER, CARÁCTER PÚBLICO, CARACTERES NACIONALES.

VARIACIONES, PERSISTENCIAS E INTERPRETACIONES EN TORNO A LA EDILICIA PÚBLICA

Daniela Alejandra CATtANeO

UN ACERCAMIENTO AL ESPACIO ARQUITECTÓNICO

FRANCISCO JAVIER FUENTES FARIAS

PÁG. 36

\section{PROPUESTA DE DISEÑO DE UN TEATRO} PARA I500 ESPECTADORES

UNA MIRADA DESDE LOS ORÍGENES DE ESTA TIPOLOGÍA ARQUITECTÓNICA

NORA ALVARIÑO TAPIA

ERNESTO FELIPE SÁNCHEZ

GRANDES IDEAS DEL MUNDO:

\section{UNA REALIDAD CONCRETA}

TENSIONES EN LA VIVIENDA UNIFAMILIAR MODERNA, OSORNO, CHILE

Hugo EduARdo Weibel FERNÁNDEZ

ESTUDIO Y GESTIÓN DE ESTÁNDARES MÍNIMOS DE FLEXIBILIDAD EN LA VIVIENDA SOCIAL EN BOGOTÁ

ROLANDO ARTURO CUBILLOS GONZÁLEZ

ESTRATEGIA DIDÁCTICA PARA EL APRENDIZAJE DE LA HISTORIA Y LA TEORÍA DE

LA ARQUITECTURA

MAYERLY ROSA VILLAR LOZANO

\section{LO MISMO MUY DE OTRA MANERA}

SOBRE LA RELACIÓN ENTRE PROYECTO Y ANÁLISIS EN EL APRENDIZAJE DE LA COMPOSICIÓN ARQUITECTÓNICA

RAFAEL FRANCESCONI LATORRE

\section{TIPO, ANÁLISIS Y PROYECTO}

GERMÁN DARÍO RODRÍGUEZ BOTERO

TRAZO DE LAS BÓVEDAS DE NERVADURAS MEXICANAS DEL SIGLO XVI

NATALIA GARCÍA GÓMEZ

CONCEPTUALIZACIÓN DE UN MODELO DE INTERVENCIÓN URBANA SOSTENIBLE

ECOBARRIOS EN EL CONTEXTO LATINOAMERICANO DE RECIENTE INDUSTRIALIZACIÓN

ADRIANA PATRICIA LÓPEZ VALENCIA

OSWALDO LÓPEZ BERNAL 


\section{EDITORIAL}

\section{¿HACIA DÓNDE VA LA PRODUCCIÓN ESCRITA EN ARQUITECTURA?}

La producción escrita en el campo de la arquitectura tiene diversas facetas, pero poco a poco ha migrado hacia la producción científica; al respecto, es de resaltar el creciente número de revistas que se orientan hacia la divulgación de resultados de investigación. Particularmente en nuestro país, años atrás solo eran unas pocas las encargadas de esta labor, entre esas la Revista de Arquitectura. Hoy en día el número crece, ya se pueden contar en la plataforma Publindex (2012) diez publicaciones que comparten este interés (no todas indexadas); a este número se le pueden agregar algunas que abordan otras áreas del conocimiento y que hacen parte del fundamento epistemológico de la disciplina, como el planeamiento urbano y regional, la historia o algunas que presentan temas de arquitectura y ciudad vistos desde el arte.

Es cierto que esta tendencia creciente es un buen indicador para el área de la arquitectura y el urbanismo, aunque si se compara con otras áreas de conocimiento la producción científica escrita todavía evidencia un bajo desarrollo. La cultura del libro en el campo arquitectónico se mantiene como una fortaleza, muchas investigaciones se presentan más en este formato que como artículos; en nuestro contexto es fácil reconocer algunos autores vinculados con la producción de libros, pero al mirarlos en relación con la producción de artículos sus nombres desaparecen.

Tampoco se puede desconocer el papel que han jugado las publicaciones "no científicas" en la documentación de nuestro acervo arquitectónico y urbano como lo fue Proa, en su momento, o la Revista Escala, la cual cumple cincuenta años en esta labor y cada día muestra más el contexto latinoamericano. A nivel internacional muchas revistas de este tipo fueron guiadas por maestros de la arquitectura y se convirtieron en espacio de discusión de nuevos postulados y teorías que guiaron el horizonte de la disciplina. Este "otro" tipo de publicaciones es complemento obligado de las publicaciones científicas, ante las cuales muchas de estas se muestran como el inicio de un cambio de cultura en la manera de ver y pensar la arquitectura y, como todo cambio cultural, necesita de tiempo y de compromiso.

La Revista de Arquitectura, inscrita en el marco del Proyecto Educativo Institucional (PEI) y del Proyecto Educativo del Programa de Arquitectura (PEP), es un espacio de discusión de los compromisos y las miradas propias del programa; la visión del proyecto como unidad totalizadora, el diseño concurrente como síntesis de diferentes campos de conocimiento, la pedagogía y la didáctica como medios de transformación de las personas, entre otros, son temas que se ven reflejados en cada edición de la publicación.

A partir de las convocatorias para postulación de artículos, y en los últimos volúmenes publicados, se pueden detectar tendencias de investigación en las cuales el tema urbano y el proyecto son dominantes, aunque el primero ha disminuido su participación.

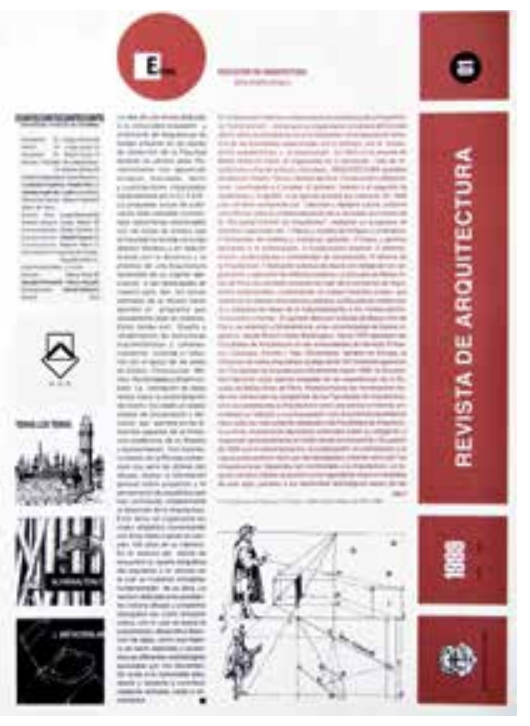

४ Figura 1

Primer número de la Revista de Arquitectura

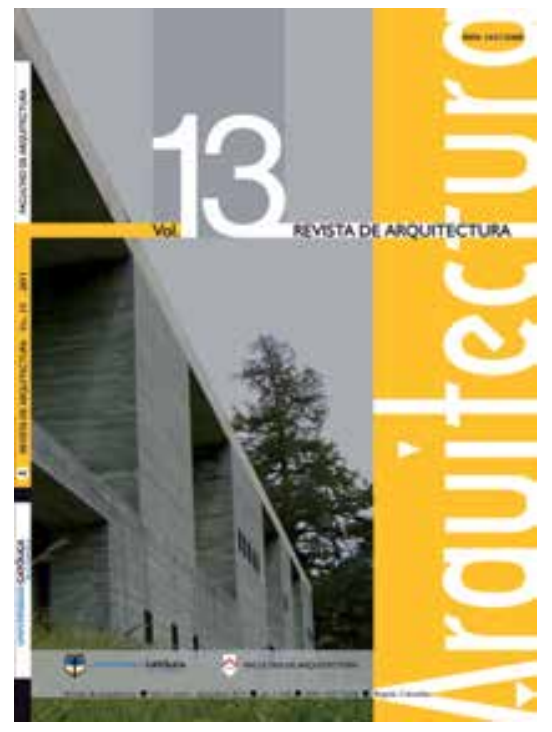

( Figura 2

Volumen 13 de la Revista de Arquitectura

La sección de "Cultura y espacio urbano" ha sido orientada por las miradas sobre temas como imaginarios y representaciones sociales e historia urbana. "Proyecto arquitectónico y urbano" ha ocupado mayor protagonismo y se pueden destacar diferentes frentes de acción, como la historia y la crítica arquitectónica, la construcción del proyecto como problema formal, espacial y social, así como la pedagogía y la didáctica en la arquitectura.

La sección "Tecnología, medioambiente y sostenibilidad" es aquella en la cual la participación es más escasa, sus temas recurrentes son los sistemas informáticos y estructurales, junto con los materiales. La baja producción en esta sección es extraña, ya que los tres componentes que la conforman son los más tratados en los discursos actuales —no solo de la arquitectura-, son realidades del mundo contemporáneo sobre las cuales la academia debería trabajar con mayor fuerza. Los cambios en estos temas son vertiginosos y las universidades y la industria tienen una gran responsabilidad al respecto.

La producción escrita se debe fortalecer, el trabajo en comunidades académicas es indispensable para continuar con este cambio de cultura; los autores, los evaluadores y las instituciones deben ser conscientes de la calidad y del rol que juegan en el avance del conocimiento, se debe buscar el acercamiento con la empresa y el sector productivo y, sobre todo, trascender las fronteras para garantizar la divulgación y la apropiación del conocimiento. 


\section{CONCEPTUALIZACIÓN DE UN MODELO DE INTERVENCIÓN URBANA SOSTENIBLE}

\section{ECOBARRIOS EN EL CONTEXTO LATINOAMERICANO DE RECIENTE INDUSTRIALIZACIÓN}

\author{
ADRIANA PATRICIA LÓPEZ VALENCIA \\ Universidad del Valle, Escuela de Arquitectura. Grupo Hábitat y Desarrollo Sostenible \\ López Valencia, A. P., \\ y López Bernal, O. \\ Conceptualización \\ de un modelo de \\ intervención urbana \\ sostenible. Ecobarrios \\ en el contexto \\ latinoamericano \\ de reciente \\ industrialización. Revisto \\ de Arquitectura, 14 \\ II6-127. \\ Arquitecta, Universidad del Valle. \\ Especialista en Gestión Ambiental, Universidad Autónoma de \\ Occidente. \\ Magíster en Urbanismo, Universidad Nacional de Colombia. \\ Candidata a PhD en Ciencias Ambientales, Universidad del Valle. \\ Ganadora del premio Green Talents 2010 del Ministerio de \\ Educación e Investigación de Alemania por sus avances en la investi- \\ gación sobre sustentabilidad urbana. \\ Profesora e investigadora de la Escuela de Arquitectura de la \\ Universidad del Valle. \\ adriana.lopez@correounivalle.edu.co
}

\section{OSWALDO LÓPEZ BERNAL}

Universidad del Valle, Escuela de Arquitectura. Grupo Hábitat y Desarrollo Sostenible

\author{
Arquitecto, Universidad Católica de Colombia. \\ Magíster en Gestión Ambiental Urbana, Universidad Javeriana. \\ Doctor en Urbanismo, Universidad Nacional Autónoma de México. \\ Realizó estancia posdoctoral en la Universidad de Montreal como \\ parte del programa de Faculty Research Program del Gobierno \\ canadiense. \\ Profesor e investigador de la Escuela de Arquitectura de la \\ Universidad del Valle. \\ oswaldo.lopez@correounivalle.edu.co
}

\section{INTRODUCCIÓN}

Este texto se presenta como parte de la investigación de tesis doctoral del programa en Ciencias Ambientales de la Universidad del Valle, a partir de la idea de proyectar un modelo de intervención urbana denominado "ecobarrio" que, aplicado al desarrollo de asentamientos localizados en áreas de vocación industrial, contribuya al mejoramiento de las condiciones de sustentabilidad urbana de estos, buscando reducir sus condiciones de vulnerabilidad ante conflictos ambientales identificados, mediante dos componentes básicos del modelo: el diseño urbano y la planeación participativa, como pilares sobre los cuales se desarrolle una propuesta contextualizada a partir de las necesidades y condiciones particulares de los países latinoamericanos.

El texto, en primera instancia, resalta la importancia del conocimiento de las variables locales y su influencia en los cambios globales y viceversa (Cohelo et al., 2010; Marston, 2005; Borja y Castells, 1998), proponiendo una serie de componentes y escalas que permitan realizar un diagnóstico de los asentamientos urbanos en su contexto, a fin de desarrollar una propuesta conceptual que involucre los diferentes factores que participan en el proceso de consolidación de un asentamiento urbano sostenible en el ámbito latinoamericano.

El artículo se estructura en tres partes, en la primera se resalta la importancia de la escala local en los procesos de intervención urbana con el fin de alcanzar un mejor nivel de sustentabilidad global; en la segunda se identifican los aspectos más relevantes para la evaluación de la vulnerabilidad de los asentamientos urbanos y su capacidad de enfrentar los impactos de su propio contexto en relación con los cambios globales; finalmente, se presentan los resultados iniciales en la búsqueda de un modelo de intervención urbana denominado "ecobarrio", aplicable al contexto latinoamericano.

Como punto de partida es necesario entender que la sustentabilidad urbana en Latinoamérica está ligada con la reducción de la vulnerabilidad frente a los conflictos ambientales ante los cuales se ven expuestos los asentamientos humanos (Clark y Dickson, 2003; Davoudi y Layard, 2001; McGill, 2001; UN, 1993). La ciudad en el mundo "en desarrollo" no puede contemplar las mismas estrategias de intervención que el mundo "desarrollado", 
si bien es cierto que ambos apuntan hacia modelos sostenibles de consumo y al mejoramiento de la calidad de vida de la población, las condiciones urbanas, sociales, económicas, ambientales, culturales y políticas son completamente distintas (Lehman, 2010; UN Habitat, 2009; McGranahan, 2003).

Mientras por un lado, la pobreza y la exclusión social, la baja calidad de los asentamientos de origen informal, el aumento de los impactos del cambio climático, los problemas relacionados con la salud en las áreas urbanas y la creciente industrialización ponen de manifiesto la creciente vulnerabilidad y los riesgos de las ciudades localizadas en los países en desarrollo. Por otro lado, las ciudades del mundo desarrollado se preocupan principalmente por la eficiencia energética de sus edificaciones, la movilidad alternativa, el "enverdecimiento" de los espacios urbanos, la competitividad en términos de atracción cultural y el desarrollo de nuevas tecnologías (Lehman, 2010; Beatley, 2000). Ambos enfoques son sin duda alguna necesarios para conseguir la sustentabilidad urbana, $y$ en el contexto de intervención de la ciudad latinoamericana requieren tener un punto de encuentro en el cual se pueda responder tanto a las problemáticas locales como a las exigencias globales.

A la luz de los cambios mundiales del medioambiente y los cambios socioeconómicos, estas ciudades latinoamericanas son también áreas que ofrecen nuevas oportunidades económicas, sociales y políticas, dadas principalmente por la aglomeración de recursos, las economías de escala y la densidad (Li, 2003), cuyas estrategias de intervención para aprovechar al máximo esas ventajas deben necesariamente corresponder con sus necesidades propias y particulares, enfrentando las externalidades, adaptándose a los cambios y planteando formas innovadoras de inclusión al contexto global.

En algunos estudios la urbanización está catalogada como un "conductor" o "causa raíz" de la vulnerabilidad (Wisner et al., 1994), en términos de crecimiento de la población, expansión urbana, degradación del suelo y consumo, así como por el incremento de las emisiones de gases de efecto invernadero como producto del desarrollo urbano (industrias, transporte y uso de la energía en los edificios).

La importancia de analizar los aspectos en los cuales un asentamiento urbano es vulnerable está enfocada en una búsqueda de la reducción de las "debilidades" que pueda tener frente a los conflictos ambientales que se presentan (Clichevsky, 2000), entendidos no solo como aquellas amenazas de origen natural, sino en la expresión más amplia del término ambiental — que involucra diferentes aspectos de la realidad y sus relaciones(Foladori, 2005; Pesci, 2000), caracterizando la ciudad industrial contemporánea y los efectos derivados de ese proceso de industrialización reciente (Barles, 2010; Satterhwaite, 2009). Por tanto, la evaluación de cada uno de los componentes mencionados está orientada hacia la determinación de la vulnerabilidad de los asentamientos, incorporando aspectos naturales, sociales y tecnológicos entre las amenazas ante las que están expuestos, las cuales provienen de aspectos propios del desarrollo urbano, que para el caso analizado en este texto se enfocan en América Latina.

Las ciudades latinoamericanas $y$, en general, aquellas pertenecientes a países en desarrollo, están actualmente expuestas a amenazas naturales constantes que han sido amplificadas debido a los efectos del cambio climático global. La mayoría de las ciudades que enfrentan los más altos riesgos son aquellas que tienen menores emisiones de gases de efecto invernadero en la atmósfera dado su reciente inicio de las etapas de industrialización (Satterthwaite, 2007), ciudades que hasta ahora no habían tenido grandes contribuciones a la problemática mundial ambiental, sin embargo, son aquellas que deben enfrentar algunos de los más fuertes impactos.

Estas áreas urbanas tienen también serias limitaciones en cuanto a su capacidad de adaptación frente a los problemas ambientales de origen antrópico, entre los que pueden identificarse los tecnológicos y sociales: contaminación del aire y del suelo, malos hábitos de consumo, insuficiencia de recursos financieros y falta de educación, como algunos de los aspectos amenazantes ante los cuales tanto la población como su entorno deben generar una respuesta estratégica que permita su propia sustentabilidad.

La intención principal del análisis enfocado hacia la vulnerabilidad que se describe en este documento es determinar los componentes principales que puedan garantizar la sustentabilidad de los asentamientos analizados a partir de la transformación del entorno construido y de las relaciones sociales para su implementación, para lo cual se toma como punto de partida el concepto de Desarrollo Sostenible de donde se desprenden objetivos específicos que puedan ser modificados en la escala local, y que son analizados a través del desarrollo del texto, llegando finalmente a los primeros resultados de la propuesta de un modelo de intervención urbana sostenible aplicable al contexto latinoamericano actual.

\section{PIENSA GLOBAL, ACTÚA LOCAL}

Desde hace veinte años los científicos han empezado a mostrar las evidencias del calentamiento global (IPCC, 2007), lo que ha ocasionado que los temas ambientales se conviertan en parte fundamental de las agendas de cada país, en donde los gobernantes tienen un rol fundamental, y es evidente que las ciudades en los próximos años tendrán que ser distintas.

La preocupación fundamental de la ciudad del denominado "primer mundo" es cómo proyectar el diseño urbano cero-carbono y el diseño arquitectónico sin el uso de combustibles fósiles; 
sin embargo, asegurar la eficiencia energética de las edificaciones no es suficiente para resolver la complejidad de las problemáticas ambientales a las que se enfrenta el mundo en general (Mostafavi y Doherty, 2011; Lehman, 2010). Por ello, es necesario implementar estrategias urbanas para la ciudad y los barrios que metodológicamente puedan ligarse con los aspectos sociales y económicos al mismo tiempo.

Desde las anteriores preocupaciones emerge el concepto de "ecociudad", descendiente del "Green urbanism", denominado así en el mundo anglo, como una respuesta en forma de "revolución pacífica" en contra de los antiguos e insostenibles métodos y prácticas de diseño urbano (Coyle y Duany, 2011; Lehman, 2010; Beatley, 2000). La ecociudad, como respuesta a los cambios y problemas urbanos, intenta reestructurarlos y transformarlos desde los estilos de vida y la forma en la que construimos y operamos las ciudades (Ritchie y Thomas, 2008), es en ellas donde se consume más energía y se producen más desechos, es por ello que es en la ciudad donde es más fructífero iniciar la batalla contra el cambio climático como problema global.

Es importante entonces contextualizar el estudio de las ecociudades en el ámbito latinoamericano, en el cual las necesidades y las características del territorio son diferentes y también sus riesgos frente a los procesos que en ellas se desarrollan. La idea de una ecociudad en Latinoamérica parte de la noción de construir un perfil de esa ciudad contemporánea, donde la industria está aún presente en sus formas "primitivas", donde la legislación aún es permisiva y la cultura marca una gran diferencia frente otros contextos geográficos en la implementación de un proyecto denominado ecociudad.

Desde esta perspectiva, la idea de ecociudad aparece como un proceso de transformación global (Verdaguer, 2010) en el cual sus piezas se convierten en elementos claves de dichos cambios dada la capacidad que tienen de intervenirse rápida y efectivamente al mismo tiempo que generan un impacto real en las demás escalas dentro de las cuales están inmersas. Estas piezas efectivas en la transformación urbana hacia la sustentabilidad pueden ser interpretadas como los barrios, en los cuales tanto los procesos sociales como aquellos que tienen relación con el ambiente construido toman forma de manera evidente y pueden ser analizados e intervenidos más fácilmente.

Como expresión cultural, el barrio hace parte de la definición de territorio local que puede ser comprendido por una comunidad bajo un imaginario de identidad colectiva, en el cual suceden las prácticas urbanas, y surgen las transformaciones espaciales endógenas y exógenas que vinculan el espacio a través de sus escalas físicas y virtuales a partir de redes jerarquizadas. La noción de territorio no se reduce a la expresión física de un escenario contenedor de los elementos naturales o artificiales, es en cambio el espacio de los flujos, los significados y la representación de las relaciones entre elementos vivos e inertes que coexisten en diferentes dimensiones dentro de un "orden". El territorio sería el "espacio apropiado y valorizado — simbólica e instrumentalmentepor los grupos urbanos" (Giménez, 2000).

Por tanto, la escala local que denominamos barrio es lo suficientemente pequeña para innovar y actuar de manera rápida y efectiva, siendo a la vez lo suficientemente grande para lograr un impacto significativo (Alonso, 2011). Es a partir de esta idea que se desarrolla conceptualmente la propuesta de ecobarrio para contribuir con el mejoramiento de la sustentabilidad urbana, actuando de manera local y verificando su incidencia en las escalas regional, nacional y global a partir de la propuesta de estrategias que puedan ser medidas con indicadores que impacten las metas trazadas a nivel mundial para la reducción de las problemáticas ambientales.

\section{Metodología}

El desarrollo metodológico de la investigación implica el abordaje de diferentes conceptos asociados con la sustentabilidad en la ciudad, por ello es necesario ligar tanto el marco conceptual como la metodología para la comprensión del modelo propuesto y las posibilidades prácticas de su implementación.

\section{LA SUSTENTABILIDAD LOCAL}

El desarrollo sostenible se ha incluido en los temas que conciernen a la planificación y el diseño del territorio, añadiendo nuevos criterios, nuevas formas de pensar acerca de las relaciones y consecuencias del desarrollo, visto como crecimiento o, mejor aún, como cambio (Satterthwaite, 2009) hacia nuevos ideales acerca de lo que se considera una "buena ciudad" o un "buen paisaje urbano".

También ha dado lugar a profundos cuestionamientos institucionales sobre el rol que deberían tomar los actores involucrados: "quién hace qué", dónde recaen las responsabilidades para dirigir los cambios ante los problemas ambientales y cuáles son las relaciones existentes con otros factores económicos y sociales (Davoudi y Layard, 2001).

El término desarrollo sostenible es ampliamente conocido, habiéndose iniciado el debate con el informe Brundtland en 1987, fruto de los trabajos de la Comisión Mundial de Medio Ambiente y Desarrollo de las Naciones Unidas; en este artículo se tomará el concepto de sostenibilidad y sustentabilidad indiferentemente a fin de no entrar en la discusión etimológica y referido siempre hacia la definición adoptada en la conferencia de Río como resultado del debate mundial que se venía presentando: "Satisfacer las necesidades de las generaciones presentes sin comprometer 
las posibilidades de las del futuro para atender sus propias necesidades" (UN, 1993).

El desarrollo sostenible implica, entonces, un nuevo estilo de políticas de gobierno para las cuales los países aún están preparándose y, aún más, implica conocer profundamente las necesidades y las debilidades que tienen tanto los habitantes como su entorno, para enfrentar los cambios y asumir el reto de convertirse en modelos de sustentabilidad, potencializando así la idea mundialmente aceptada en la cual se expresa que el desarrollo sostenible no podrá ser alcanzado en una relación jerárquica de "arriba hacia abajo" únicamente (Davoudi y Layard, 2001), sino que debe abarcar la generación de estrategias desde el centro del problema.

Siguiendo la idea de contribuir con el mejoramiento de la sustentabilidad urbana desde "adentro" (Caeiro, 2012; Cohelo et al., 2010; Borja y Castells, 1998), se propone dar una mirada tanto al asentamiento urbano analizado en sus aspectos ecológicos y espaciales, como a sus relaciones sociales, económicas y políticas desde la óptica de la vulnerabilidad, entendida esta no solo frente a eventos que pueden ocurrir sino también como producto de factores políticos y económicos estructurales (Adger et al., 2003; Pelling, 1999).

La vulnerabilidad puede ser comprendida desde diferentes escuelas de pensamiento entre las que se destacan la de Bohle (2001) en la cual la vulnerabilidad puede ser vista desde un punto interno y uno externo, el primero es la capacidad de anticipar los eventos, hacer frente a ellos y recuperarse del impacto de una amenaza determinada, en contraste con el segundo, que involucra el grado de exposición ante dichas amenazas. Otra escuela es la de Davidson (1997), que define la vulnerabilidad como un componente del riesgo ante los desastres, diferenciando entre exposición, vulnerabilidad y capacidad de respuesta.

Turner et al. (2010) consideran la incorporación del concepto de adaptación como un elemento que incrementa la resiliencia —entendida esta como la capacidad para recuperarse después de un evento-; esta aproximación al concepto de vulnerabilidad incorpora además un vínculo con el ambiente humano, haciendo de su interpretación un concepto un poco más amplio. Wisner et al. (1994) desarrollan la idea desde la economía política, buscando las causas, las presiones dinámicas y las condiciones inseguras que determinan la vulnerabilidad.

Finalmente, Birkmann et al. (2006) desarrollan un marco conceptual que localiza la vulnerabilidad en un sistema cíclico —que tiene en cuenta el tipo de amenazas, los potenciales eventos y las interacciones entre la sociedad, la economía y el entorno natural frente a su exposición a dichos eventos- en el que es necesaria la inclusión de las dimensiones social, económica y ecológica, creando así un vínculo hacia el desarrollo sostenible.
En el desarrollo de esta investigación se tomó el concepto de vulnerabilidad como sistema cíclico el cual debe tener en cuenta las amenazas según su tipo, incorporando los aspectos sociales y económicos, además de aquellos eventos a los que un asentamiento y su población están expuestos. Esto significa que en la búsqueda de la sustentabilidad urbana es necesaria la reducción de la vulnerabilidad de los asentamientos (Conte y Monno, 2012; Kappes et al., 2012; Daniel y Ortmann, 2011; Turner, 2010; Briguglio et al., 2009; Nelson et al., 2007; Adger, 2006; Gallopin, 2006; Folke et al., 2002), lo que implica mejorar su capacidad de adaptación al cambio climático y el reconocimiento de los límites sociales y ecológicos (Brikmann, 2006).

Desagregando el concepto de sustentabilidad urbana para ser comprendido bajo su finalidad, componentes y objetivos, se llega a la definición de cuatro subsistemas de evaluación e intervención: económico, social, ecológico (UN Hábitat, 2009; Allen et al., 2002; UN, 1993) y físico-espacial (López y Camelo, 2008) como componentes fundamentales para la determinación del nivel de sustentabilidad en un área urbana.

Estos componentes son agrupados en dos finalidades específicas: la equidad (Vallance y Perkins, 2011; Godschalk, 2004; Sachs, 1999) entendiendo que los componentes económico y social propenden por el balance existente entre los objetivos de productividad y calidad de vida respectivamente (Chiu, 2003; Crabtree, 2005), considerando el balance en las condiciones

\footnotetext{
(1) Figura 1.

Finalidad, componentes y objetivos para la evaluación del territorio Fuente: elaboración propia.
}

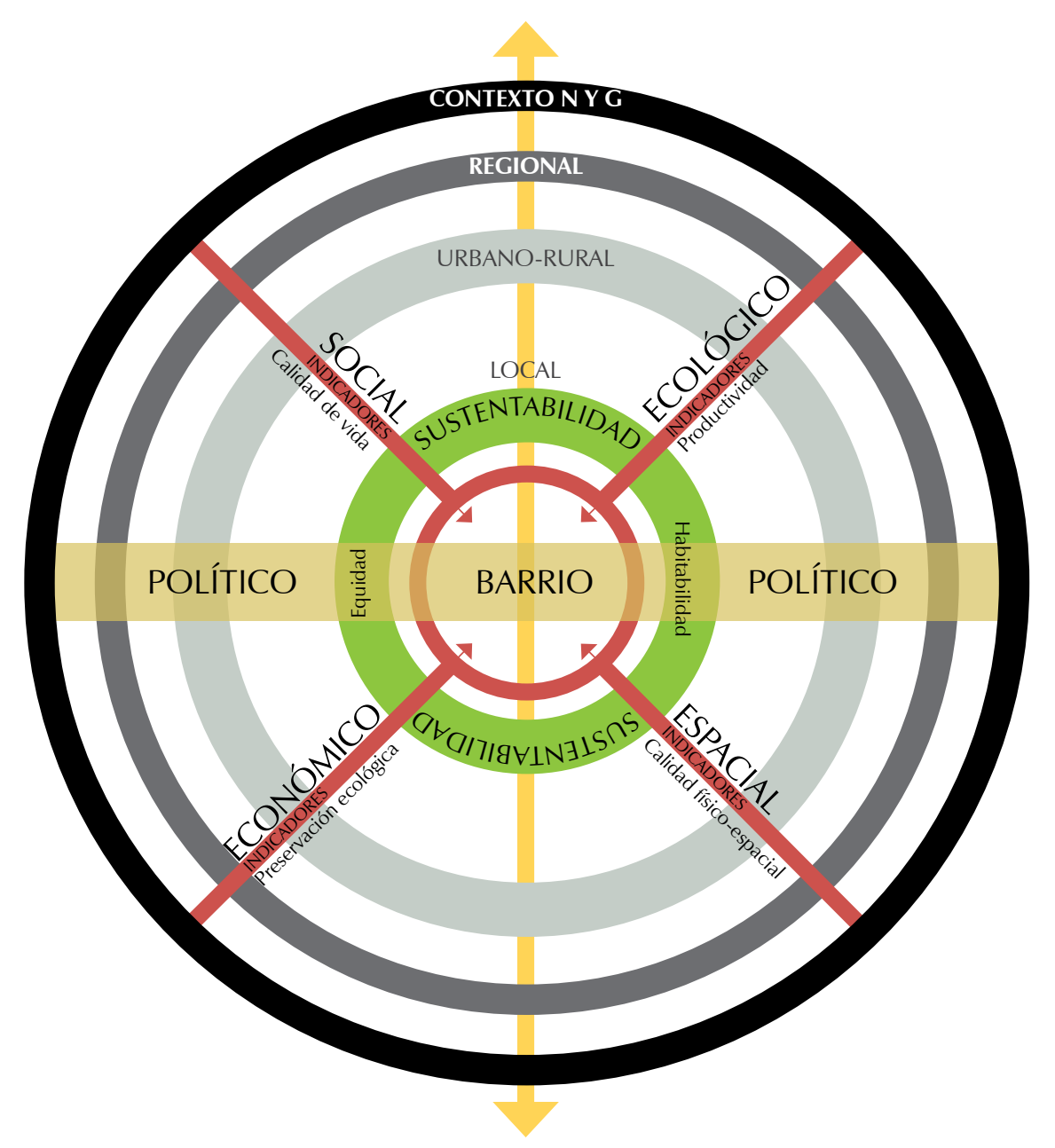


Formación de asentamientos de informalidad con reducida posibilidad de acceso a equipamientos, saneamiento básico, infraestructura, espacio público y bajos niveles de productividad, en un ambiente contaminado, poco habitable e inmersos en un contexto de cambio climático mundial

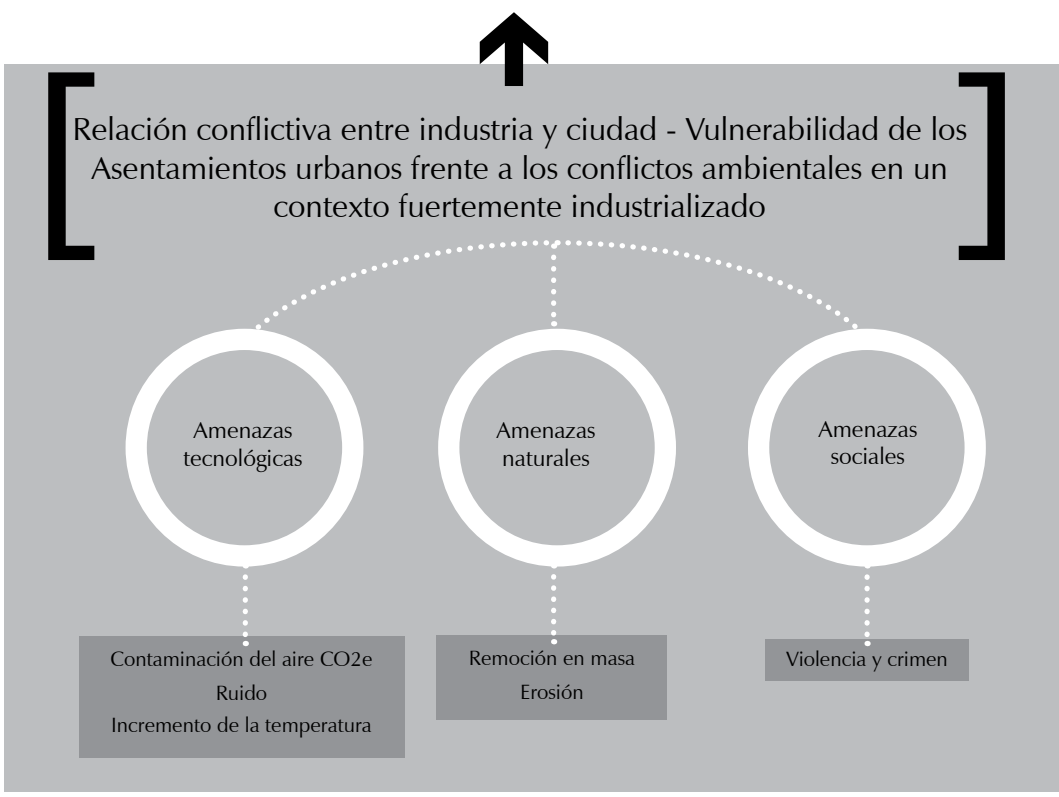

(A) Figura 2

Conflictos ambientales identificados

Fuente: elaboración propia. "intangibles" del territorio (Foladori, 2005); y la habitabilidad (Satterthwaite et al., 2007; EngelYan, 2005) como segunda finalidad, demostrando las áreas tangibles donde se buscan los objetivos enfocados hacia la preservación ecológica y la calidad físico-espacial (Haapio, 2011; Lazzeri y Moustier, 2008; Clark y Dickson, 2003).

Una vez comprendidos estos aspectos, es necesario contar con un subsistema de administración y decisión (López Valencia, 2011) denominado el componente político cuya finalidad es servir de "filtro" para la sustentabilidad, como un subsistema gestionador (Folke, 2006) y a través del cual las estrategias planteadas en el territorio desde lo tangible e intangible puedan llegar a tomar forma y materializarse efectivamente (UN Habitat, 2008; Clark y Dickson, 2003; Miltin, 2000). La figura 1 resume los principales aspectos hasta aquí expuestos, y muestra al barrio como punto central hacia el cual se debe enfocar el análisis, involucrando las escalas del contexto y buscando incorporar las implicaciones de las actuaciones locales en ellas (Conte y Monno, 2012; Cohelo et al., 2010; Marston, 2005; Bussemey y Achard, 1997).

Para la selección de las variables y los indicadores con los cuales se va a evaluar cada uno de los objetivos es necesario también comprender los conflictos ambientales a los que se enfrenta el asentamiento analizado, para lo cual se ha tomado el caso de Yumbo, Valle en Colombia como escala local, un municipio de aproximadamente 100.000 habitantes localizado al norte de la ciudad de Cali - la tercera ciudad en importancia y tamaño en Colombia- y en el cruce de las rutas que desde la capital del país llevan hacia uno de los puertos de carga más importantes (Buenaventura), y hacia la conexión internacional con el sur del continente americano, lo que ha consolidado este municipio como un polo de desarrollo industrial desde 1946, ubicándolo en la categoría de ciudades de reciente industrialización descritas anteriormente.

A partir de esta aproximación se seleccionó un barrio de origen informal que presentara problemáticas relacionadas con su cercanía a las industrias, el barrio Las Américas fue el asentamiento urbano escogido, localizado en zona de ladera y cuya escala permite la implementación del concepto de Ecobarrio (Alonso, 2011; Verdaguer, 2000; Rudin y Falk, 1999) en un contexto de alta industrialización. Siendo un asentamiento de aproximadamente cincuenta años, en el cual sus habitantes llegaron en busca de terrenos de bajo costo cercanos a las fuentes de trabajo, se consolidó como un barrio en el cual a lo largo del tiempo se comenzaron a evidenciar los problemas relacionados con su localización, un tanto privilegiada en términos productivos, pero que no aporta suficientemente para lograr su sustentabilidad.

Los principales conflictos ambientales asociados al proceso de urbanización de esta área se enfocan en tres amenazas principales: las de origen natural (Solecki et al., 2011; Hallegate, 2009; Romero-Lankao, 2007), las tecnológicas (Hardoy et al., 2011; Kuntsi-Reunanen, 2001), y las sociales (McGranahan y Satterthwaite, 2011; Adger, 2006). En la figura 2 se observan estas amenazas, así como sus repercusiones en el territorio.

Una vez determinados los conflictos ambientales que interesa analizar, las variables seleccionadas para cada componente corresponden con la búsqueda de la reducción de la vulnerabilidad frente a ellos, es decir, son seleccionadas teniendo en cuenta el potencial que pueda tener una estrategia de mejoramiento en determinado aspecto para ser validado bajo un análisis de escenarios posibles (Lempert et al., 2006; Maclaren, 1996).

\section{RESULTADOS}

\section{COMPONENTES PARA EVALUAR LA SUSTENTABILIDAD LOCAL}

A partir de la identificación de los conflictos ambientales se proponen una serie de componentes y objetivos mediante la formulación de variables e indicadores que buscan evaluar la vulnerabilidad de los asentamientos seleccionados con respecto a las amenazas. Posteriormente se generan estrategias tendentes a la reducción de estas vulnerabilidades, lo que finalmente llevaría al mejoramiento de las condiciones de sustentabilidad de las áreas en las que logre implementarse efectivamente un modelo de intervención que involucre dichas estrategias (Turner, 2010; UN Habitat, 2008; Birkmann et al., 2007; Adger, 2006). 


\section{COMPONENTE ECONÓMICO}

En el componente económico — cuyo objetivo principal es el mejoramiento de la productividad, dado que las ciudades son el motor de los procesos económicos y por ende del desarrollo- (Rivera-Arriaga, 1999), el análisis se enfoca hacia tres variables principales: eficiencia, innovación y producción, desde las cuales es posible la determinación de estrategias basadas en el diseño urbano y la participación, que contribuyan con el mejoramiento de la sustentabilidad urbana, pudiendo ser medidas a través de indicadores que evidencian el nivel de ingresos de la población (Sachs, 1999) y el gasto en consumo de recursos como agua y energía (Kerkhof et al., 2009) asociados a la variable de eficiencia.

La localización de actividades innovadoras, y sus vínculos con la empresa y la academia, son aspectos fundamentales por evaluar desde la variable de innovación (Acebedo, 2010; Klein, 2003; Castells y Hall, 1996), teniendo en cuenta las características de un territorio inmerso en un contexto altamente industrializado.

Finalmente, la variable producción puede evaluarse a partir de indicadores de diversidad económica (Breeam, 2009) y zonas de empleo (Godschalk, 2004; Vallance y Perkins, 2011), demostrando las debilidades de la zona en este componente a partir de su valoración en la escala local y permitiendo la generación de propuestas individuales y contextualizadas que propendan por la reducción de la pobreza.

\section{COMPONENTE SOCIAL}

La evaluación de la vulnerabilidad frente a los conflictos ambientales a los que está expuesto el asentamiento urbano se lleva a cabo bajo la identificación de problemáticas asociadas con la comunidad que habita estas áreas (Crabtree, 2005; Bhatti y Dixon, 2003) a través de indicadores agrupados en tres variables principales: bienestar, equilibrio y seguridad, demostrando los impactos en la salud de la población principalmente provenientes del contexto industrial en el que estos asentamientos están inmersos, identificando las principales causas de mortalidad asociadas a la variable bienestar (McGranahan y Satterthwaite, 2011).

En este componente es importante la valoración de aspectos de cobertura de equipamientos educativos (Vallance y Perkins, 2011; Clark, 2007) para brindar mejores condiciones de calidad de vida a la población, así como la localización de actividades comunitarias que vinculen los diferentes grupos poblacionales en los procesos de participación que tienen que ver con el desarrollo urbano del barrio, asociados a la variable de equilibrio (Casbee, 2007).
La percepción de zonas de inseguridad frente a la ocurrencia de delitos y su localización son indicadores asociados a la variable seguridad, que también debe involucrar la localización de accidentes relacionados con el contexto industrializado, teniendo en cuenta los altos flujos de movilidad vehicular pesada asociados a la actividad productiva, y los accidentes tecnológicos que puedan ocurrir por la misma (UN Habitat, 2008; Adger, 2006).

\section{COMPONENTE ECOLÓGICO}

Para la valoración del componente ecológico es necesaria la incorporación de indicadores desde la variable de Estado, buscando la identificación tanto de las condiciones de los ecosistemas como del ambiente construido, teniendo en cuenta los aspectos constructivos y las condiciones de las edificaciones para determinar las eventualidades que pueden presentarse (Kappes et al., 2012; Papathoma-Köhle, 2007; Casbee, 2007; Adger, 2005).

La variable Consumo de recursos es determinante para garantizar la sustentabilidad de un asentamiento (Conte, 2012; Caeiro et al., 2012; Mateus y Barrança, 2011; Druckman et al., 2008), por lo que es importante evaluarlos bajo indicadores que demuestran la cantidad de agua y energía utilizada en las labores y usos que se desarrollan en las áreas seleccionadas (Breeam, 2009).

Asimismo, es necesario consolidar la información sobre los tipos de tratamiento que se llevan a cabo con los desechos así como la cantidad producida (Kennedy et al., 2011; Curran et al., 2007; Girardet, 2004) a fin de establecer la gravedad de dicho conflicto en el asentamiento analizado para posteriormente generar estrategias de mejoramiento.

\section{COMPONENTE ESPACIAL}

Dado que uno de los componentes tangibles, el espacial, se refiere a los aspectos del ambiente construido y sus relaciones, es necesario conocer los hábitos que involucran problemáticas ambientales como los desplazamientos urbanos (Tukker et al., 2010; Breeam, 2009; Leed, 2009) y el tipo de vehículos utilizados, buscando una de las fuentes de contaminación del aire desde la variable movilidad.

La estructura urbana es una variable relevante (Conte, 2012) que involucra el análisis de indicadores como el uso del suelo para demostrar la monofuncionalidad o no del asentamiento. El análisis de las tipologías edificatorias que definen la densidad, unida a datos sobre las alturas de las edificaciones (Papathoma-Köhle, 2007), proporcionan información sobre la forma urbana habitada (Olazabal et al., 2008; Oswald y Baccini, 2003), incorporándose al análisis de la estructura del ambiente construido, así como a los 


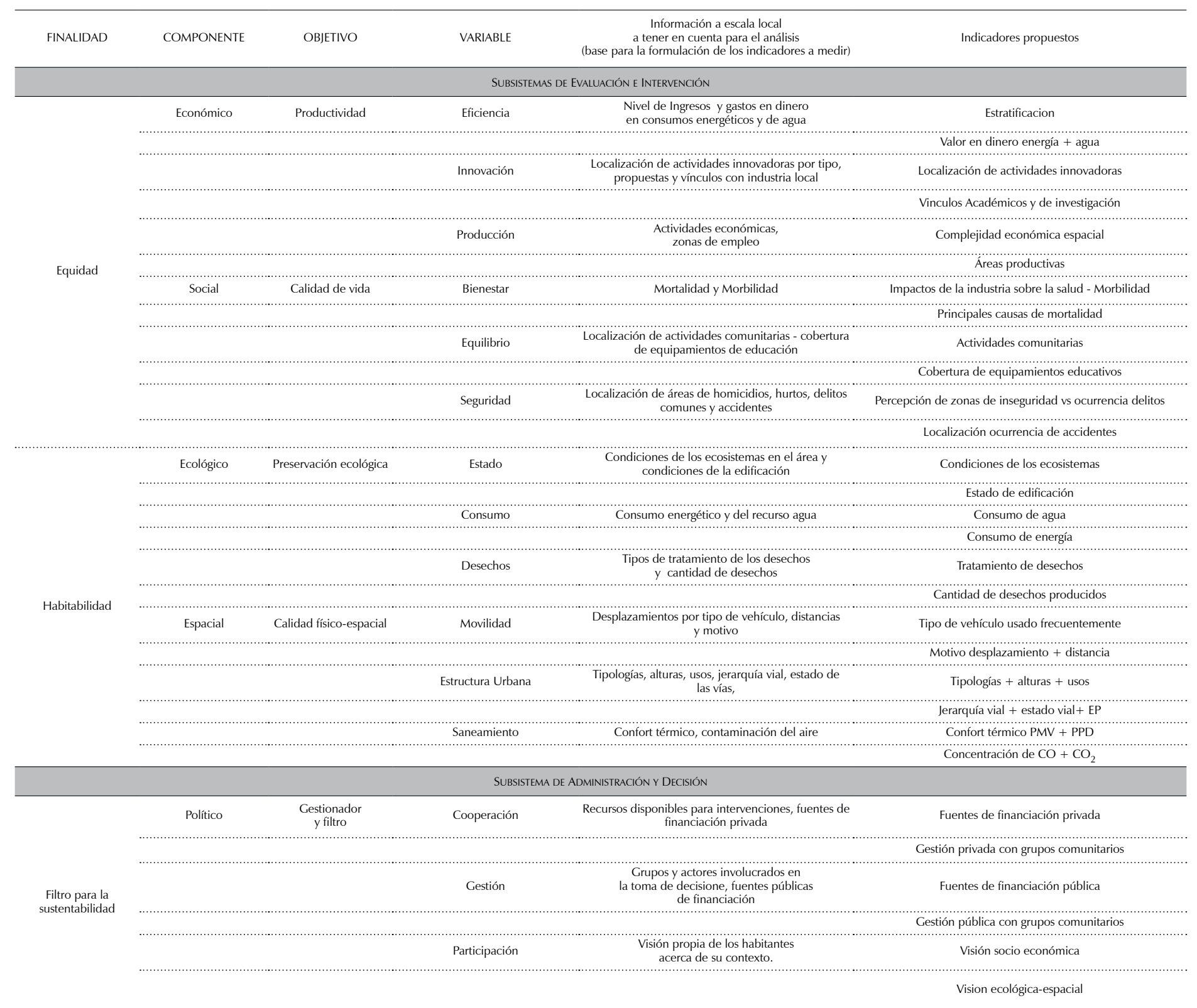

Tabla 1.

Síntesis de indicadores y relaciones con el marco teórico indicadores que muestran aspectos de las áreas urbanas "no habitadas" o de corta permanencia como el espacio público, en aspectos de calidad y cobertura, la jerarquía y el estado de las vías como elementos que determinan el desempeño urbano (Verdaguer, 2010; LEED, 2009).

La variable de saneamiento busca sobre todo identificar los efectos de la concentración de contaminación por $\mathrm{CO}_{2}$ e y sus impactos en las áreas urbanas analizadas (Kennedy et al., 2011) desde la respuesta tanto de la población, como del espacio construido. Las olas de calor como producto de los cambios climáticos globales (IPCC, 2007), hacen necesaria la evaluación del confort térmico relacionado con el espacio urbano en un clima tropical como el que interesa en esta investigación (Conte y Monno, 2012; Mateus y Barrança, 2011; Gamboa et al., 2011; Givoni, 1998), buscando la mejora de las condiciones y una propuesta de estrategias de adaptación.

\section{COMPONENTE POLÍTICO}

Como componente de "filtro", las variables y los indicadores aquí identificados funcionan como un condicionante para el logro de los objetivos planteados en los cuatro componentes anteriores. Las variables aquí analizadas buscan la evaluación de la posibilidad real de implementación de un modelo de intervención que mejore las condiciones de sustentabilidad basado en aspectos de diseño urbano (Kennedy et al., 2011; Lehman, 2010) y participación (Caeiro et al., 2012; Tukker et al., 2010), por lo que es necesario contar con información de indicadores como los recursos disponibles para inversión en la zona y las fuentes de financiación (Tol y Yohe, 2007; McGill, 2001), como áreas relacionadas con la variable de cooperación.

Es importante poder reconocer los grupos públicos y privados, así como aquellos de origen comunitario que puedan llevar a cabo la tarea de materializar las estrategias propuestas en el modelo (Du Plessis y Cole, 2011; Cohen, 2010; Seyfang, 2009; Folke, 2006) como elementos estratégicos de la variable gestión.

Finalmente, es relevante conocer la visión que tienen los habitantes de su propio contexto, tanto en el aspecto socioeconómico como en el ecológico-espacial (Ryan, 2011; Reyos, 2009), así como de los demás actores involucrados en la toma de decisiones como elementos de la variable participación, lo que permitirá trabajar desde un modelo de contribución endógeno y local. 


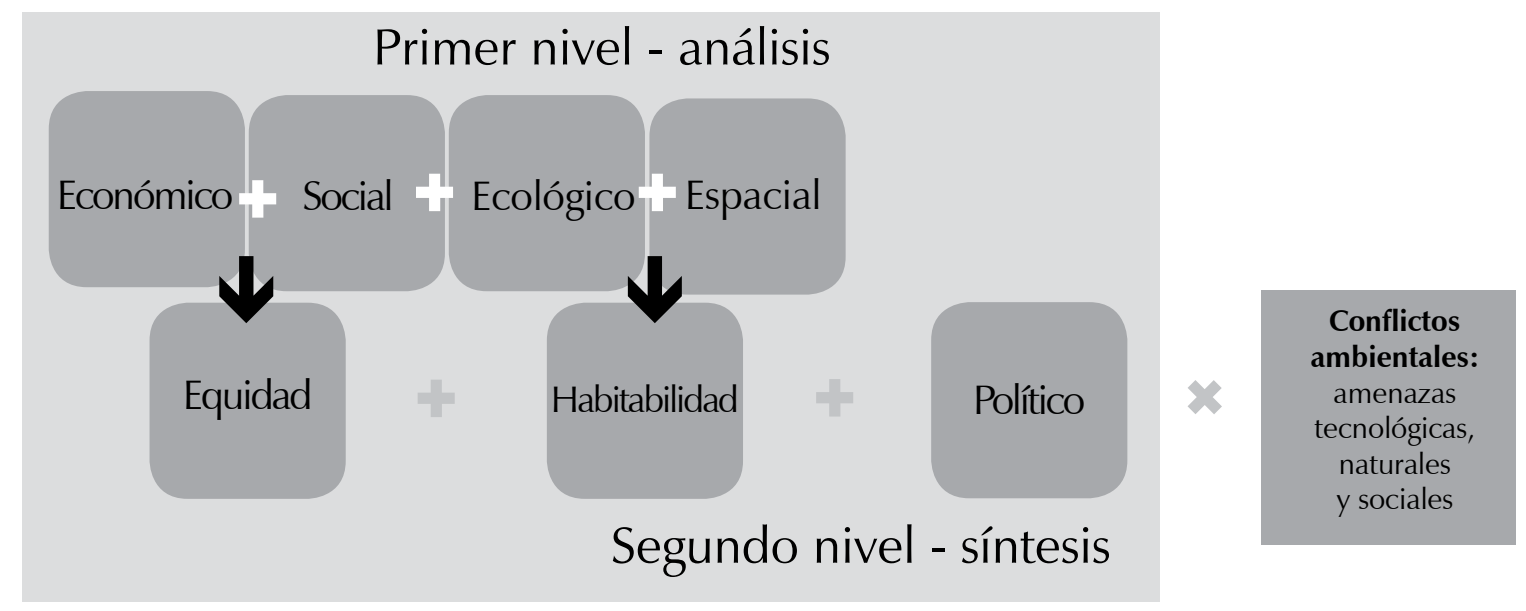

En la tabla 1 se detallan todos los indicadores con los que se determina el nivel de vulnerabilidad frente a los conflictos ambientales identificados, mostrando para cada uno de los componentes las variables y la información necesaria para la valoración diagnóstica de las áreas que se van a estudiar. El esquema de cruce de la información que se muestra en la figura 3 es el que define la forma en la que matemáticamente se agregan las variables involucradas en la evaluación de la vulnerabilidad de los asentamientos seleccionados, conformada por un primer nivel de análisis en el que se evalúan los componentes descritos hasta ahora, para determinar el estado de las áreas de estudio de manera diagnóstica y desagregada por cada componente a fin de establecer en detalle cuáles son las principales falencias encontradas.

Un segundo nivel corresponde a la síntesis en la que se agregan los subsistemas de evaluación e intervención con el subsistema de gestión y decisión, para finalmente poder determinar su nivel de vulnerabilidad frente a los conflictos ambientales identificados —tecnológicos, naturales y sociales- como amenazas ante las que están expuestos los asentamientos, teniendo así un resultado final en el que se evidencian las problemáticas del área estudiada, mapeadas y desagregadas por componentes.

En esta primera y segunda etapa de elaboración conceptual del modelo de intervención es necesario involucrar los principales actores en la definición del perfil urbano con el que se caracterizan las zonas de estudio, identificando la información pertinente a cada uno de los indicadores a partir de la participación de los grupos comunitarios, empresariales, académicos y el Gobierno, contando así con una visión real del territorio desde la escala local que es la que permite el acercamiento a las formas de ocupación y utilización del territorio.

\section{MODELO DE INTERVENCIÓN URBANA SOSTENIBLE "ECOBARRIO"}

Esta investigación presenta hasta ahora los elementos constitutivos de la evaluación conceptual para la propuesta de un modelo con el que se busca intervenir el territorio analizado, dejando claro que es necesaria la visión desde la escala local hacia lo global para que las propuestas sean sostenibles en el tiempo. La siguiente etapa en desarrollo corresponde a la valoración de las condiciones del asentamiento seleccionado para dar respuesta a las preguntas acerca de la vulnerabilidad de dicha zona frente a los conflictos ambientales con las cuales posteriormente elaborar las estrategias de mejoramiento que den forma al modelo de intervención propuesto. La figura 4 resume los avances en la elaboración del modelo conceptual de la propuesta de ecobarrio para el contexto latinoamericano.

La conformación de un modelo de intervención urbana sostenible está principalmente enfocada hacia el conocimiento local del territorio analizado, evidenciando en primera instancia los aspectos problemáticos internos de la comunidad y su entorno, desde los aspectos económicos, sociales, ecológicos, espaciales y políticos, medidos a partir de los indicadores propuestos en la tabla 1, los cuales, una vez contrastados con aquellos conflictos ambientales identificados como amenazas tecnológicas, naturales y sociales, determinan el grado de vulnerabilidad del área analizada.

Para esta evaluación el modelo prevé la participación activa de los actores (comunidad, empresa, academia, gobierno) involucrados en los procesos urbanos del barrio, logrando identificar tanto las problemáticas como las estrategias que de manera endógena puedan surgir durante el proceso de análisis y generación de lineamientos sustentables aplicables al contexto, conformando así un perfil de análisis urbano que contempla los aspectos intrínsecos de la zona y abre la posibilidad para que tanto la gestión como la implementación de las estrategias de diseño urbano generadas sean concebidas como propias y se continúen desarrollando de manera espontánea.

El principal propósito de un modelo de intervención urbana es encontrar las relaciones modificables tanto en el entorno urbano construido, como en los aspectos intangibles del territorio, a fin de generar estrategias que permitan la correcta y efectiva implementación de lineamientos
(A) Figura 3.

Método para el cruce de información de indicadores 


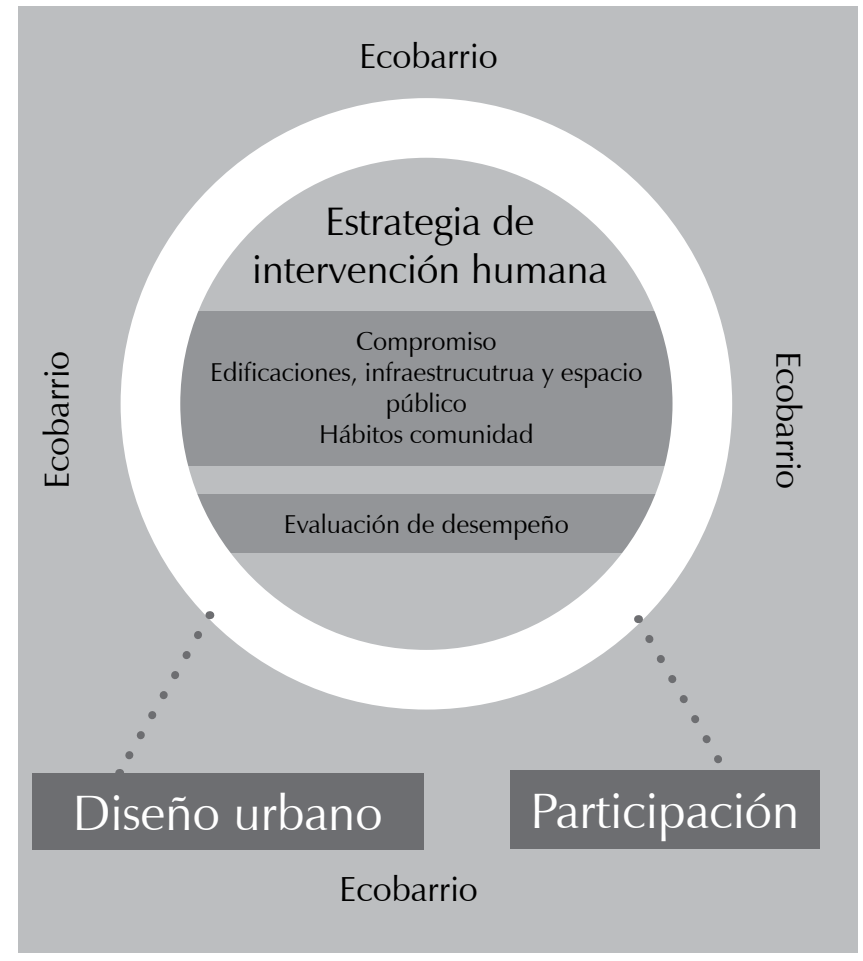

(A) Figura 4.

Componentes de la propuesta del modelo de intervención urbana sostenible "ecobarrio" amenazantes más complejas. sustentables y de adaptación a las condiciones

Los componentes que este modelo de intervención urbana propone se basan en dos pilares básicos: el diseño urbano y la planeación participativa, desarrollados a partir de la generación de lineamientos que surjan desde la escala local o del barrio y sus actores involucrados (públicos, privados y comunitarios), aplicables en cada uno de los componentes del marco conceptual (económico, social, ecológico, espacial y político) y proponiendo estrategias específicas en las que el compromiso de dichos actores, el sentido de comunidad y las actuaciones en el espacio, se combinen para dar lugar a una propuesta de intervención y manejo urbano que permita mejorar las condiciones de calidad de vida de la población en su espacio habitable, a partir de conocer su grado de vulnerabilidad frente a los conflictos ambientales ante los que están expuestos, y determinando para cada una de las problemáticas acciones concretas y realizables.

El diseño urbano surge como estrategia de intervención del territorio al ser uno de los parámetros más importantes para la conformación de la ciudad, que al conjugarse de manera eficiente con la planificación y la gestión puede cimentar bases firmes en la construcción de la misma. En oposición a esto aparecen las invasiones o los asentamientos subnormales que se caracterizan por tener un deterioro de las redes sociales y físicas de la ciudad, ya que no se han usado los instrumentos de diseño para la consolidación del espacio público y las áreas libres, donde el urbanismo y sus instrumentos se puedan ejecutar, dándole forma a los asentamientos urbanos de manera planificada y con políticas claras que contengan estándares mínimos de urbanización.
El diseño urbano es un proceso técnico-artístico que debe integrarse a la labor de planificación, debe cuidar la imagen de la ciudad, y es por excelencia uno de los instrumentos técnicos del urbanismo para la generación de un espacio público de calidad físico-espacial y confort ambiental. De igual modo, es el encargado de relacionar las características arquitectónicas y urbanísticas construidas históricamente por la población, en ella concurren tecnologías, materiales de construcción, ideas, creencias, preferencias y sensibilidades propias de cada época y grupo humano, es así como se contextualiza la intervención urbana en un lugar determinado.

El modelo de intervención que esta investigación propone basa sus principales esfuerzos en la consolidación de estrategias de diseño urbano con criterios de sustentabilidad como el confort ambiental, el control de la contaminación, la reducción de riesgos, la adaptación a la variabilidad climática y las condiciones naturales cambiantes, la eficiencia energética, la generación de espacios para el mejoramiento de la productividad y el fomento del cambio en los hábitos de consumo, aumento de la seguridad y reducción de lugares propicios para el crimen y el delito, entre otras acciones que puedan llevarse a cabo mediante la intervención del espacio construido por parte de los actores involucrados, conformando así los dos principales pilares del modelo propuesto: diseño urbano y planeación participativa, estrategias que se generan para la transformación del barrio como pieza urbana clave para la sustentabilidad de la ciudad.

\section{DISCUSIÓN}

\section{ECOBARRIO EN EL CONTEXTO LATINOAMERICANO}

De acuerdo con las definiciones consignadas en Building the 21st Century Home. The Sustainable Urban Neighbourhood, los autores Rudin Falk (1999), marcan la importancia de cada una de las palabras del término utilizado: Sustainable Urban Neighbourhood (barrio urbano sostenible). Se trata de un lugar construido, sostenible, que hace parte de una ciudad, poniendo un límite a las actuaciones en las que si bien el entorno es "lo bastante extenso como para acometer transformaciones amplias" también es interpretado como "lo bastante reducido como para que sus habitantes se sientan implicados en ellas" (Alonso, 2011).

El término ecobarrio es bastante reciente, se puede decir que hace aproximadamente solo una década que se está fomentando su uso (Verdaguer, 2010), sin embargo, no todas las actuaciones que se conocen con el nombre de ecobarrios lo son (Harguindeguy y Arias, 2009). Algunas propuestas titulan sus intervenciones en la ciudad con este nombre para darle una distinción "verde" al 
proyecto, pero no son más que meras actuaciones aisladas sin una concepción integral de los aspectos que una propuesta en esta vía requiere: sociales, culturales, comunitarios, de metabolismo urbano, productividad, conservación y de gestión, variables que para la elaboración del modelo aplicado a Latinoamérica son fundamentales en la definición del concepto de ecobarrio.

Propuestas similares como las ecoaldeas han sido altamente popularizadas; en lo que puede llamarse un modelo poco sostenible, estas pequeñas aldeas están tan solo interconectadas e inmersas en una localización dispersa en el territorio que ha sido demostrada como poco sostenible dada su expansión y los efectos secundarios que esta conlleva (Mostafavi y Doherty, 2011; Lehman, 2010; Beatley, 2000). El término de barrio sostenible o ecobarrio ha sido utilizado también para denominar nuevas actuaciones periféricas con criterios de autosuficiencia; no obstante, estas propuestas presentan inconsistencias con el término en sí, dada su desconexión con la ciudad y su interpretación como "suburbios verdes" que no le aportan mucho a la sustentabilidad urbana.

Un ecobarrio en el contexto urbano latinoamericano altamente industrializado deberá contemplar entonces acciones desde tres estrategias principales: el compromiso de los actores involucrados (Caeiro et al., 2012; Tukker et al., 2010), tanto la empresa privada como el gobierno local y la comunidad residente, impulsando así un sentido de comunidad local activo que permita la materialización y sostenibilidad en el tiempo de las propuestas; una segunda línea estratégica está representada por las actuaciones en las edificaciones, la infraestructura y el espacio público (Conte, 2012; Breeam, 2009; LEED, 2009), enfatizando en aquellas en las que se reducen costos, se reutilizan recursos y, sobre todo, en las que involucran procesos innovadores, eficientes y con la capacidad de adaptarse a las condiciones de cambio climático; una tercera estrategia está dada por los hábitos de la comunidad residente (Conte, 2012; Mateus y Barrança, 2011; Casbee, 2007) frente al consumo de recursos, manejo de desechos y educación para la sustentabilidad, estrategia que permitirá mejorar el metabolismo urbano de las zonas de intervención.

Finalmente, es relevante que el modelo contemple las acciones para la constante evaluación de las intervenciones con el fin de medir en la escala del barrio o local el impacto de las propuestas y la forma en la que pueden contribuir con la sustentabilidad de la zona, mejorando la vulnerabilidad encontrada. Esta evaluación está fundamentada en líneas base comparables con estándares que también permitan ver el impacto en las demás escalas: urbano-rural, regional y el contexto nacional-global, por lo que será determinante la significancia de las propuestas y el real impacto en el mejoramiento de las problemáticas locales que tengan repercusiones globales, lo que brindará una forma real de validar el modelo propuesto como ecobarrio.

\section{CONCLUSIONES}

La propuesta de indicadores a partir de variables que evalúan la vulnerabilidad del asentamiento urbano permite la comprensión de los puntos "clave" en los cuales enfocar la generación de estrategias de intervención urbana aplicables al contexto evaluado que, desde la escala local, puedan repercutir ampliamente en el mejoramiento de las problemáticas globales, por lo que es importante concebir el modelo desde lo local hacia lo global.

Al identificar los componentes involucrados para mejorar la sustentabilidad de un asentamiento en la escala local, a partir del desarrollo de indicadores, se busca conceptualizar una propuesta de intervención urbana sostenible apoyada fundamentalmente en dos aspectos: el diseño urbano y la participación.

La premisa fundamental está ligada al mejoramiento de los aspectos vulnerables para el establecimiento de estrategias locales que partan desde la intervención del entorno construido y que se generen a partir de la participación de los actores involucrados en el desarrollo urbano de la zona.

Esta búsqueda permite identificar unos principios de intervención urbana aplicables al contexto latinoamericano con el análisis de un caso experimental en Yumbo, Colombia, y que pueda ser posteriormente implementado en casos similares e incluso adaptado a las condiciones específicas en otros países en desarrollo.

El modelo de ecobarrio en el contexto latinoamericano -involucrando la industria como componente fundamental en la determinación de problemáticas aplicables a la zona- es un paso en la determinación de estrategias de mejoramiento del hábitat urbano en asentamientos de origen informal, que muestra una vía en la que pueden enfocarse las acciones urbanísticas y los procesos de planificación urbana en los países en desarrollo.

Es fundamental tener en cuenta los aspectos culturales, socioeconómicos y las relaciones que existen entre ellos en el espacio construido, siendo esta una propuesta para conformar comunidades menos vulnerables frente a los actuales procesos de cambio climático mundial. 


\section{REFERENCIAS}

Acebedo, L. F. (2010). Territorios del conocimiento en la Ecorregión Eje Cafetero. Caleidoscopios a partir de tres espejos de representación: Sociedad + Espacio + Conocimiento. Tesis de Doctorado en Urbanismo, Universidad Central de Venezuela (inédito).

Adger, W. N. (2006). Vulnerability. Global Environmental Change, 16 (3), 268-281.

Adger, W. N.; Huq, S., et al. (2003). Adaptation to climate change in the developing world. Progress in development studies, 3 (3), 179.

Adger, W. N.; Hughes, T. P., et al. (2005). Socialecological resilience to coastal disasters. Science, 309 (5737), 1036.

Allen, A. and. You, N. (2002). Sustainable urbanisation. Bridging the Gap between the Green and Brown Agendas. London: Un-Habitat, DFID and Development Planning Unit.

Alonso, N. M. (2011). Ecobarrio. Ciudades para un futuro más sostenible. Madrid: Escuela técnica superior de arquitectura de Madrid.

Barles, S. (2010). Society, energy and materials: the contribution of urban metabolism studies to sustainable urban development issues. Journal of Environmental Planning and Management, 53 (4), 439-455.

Beatley, T. (2000). Green urbanism: Learning from European cities, Island Pr. Bhatti, M. and Dixon, A. (2003). Introduction to special focus: Housing, environment and sustainability..Housing Studies, 18 (4), 501-504

Birkmann, J. (2006). Measuring vulnerability to promote disaster-resilient societies: Conceptual frameworks and definitions. Measuring vulnerability to natural hazards: Towards disaster resilient societies. Tokyo: United Nations University Press. (9-54).

Birkmann, J.; Fernando, N., et al. (2007). Rapid vulnerability assessment. Source Publication Series of UNU-EHS (7).

Bohle, H. G. (2001). Vulnerability and criticality: perspectives from social geography. IHDP update, 2 (01), 3-5.

Borja, J. and Castells, M. (1998). Local y global. La gestión de las ciudades en la era de la información. Madrid: Santillana.

Breeam, C. (2009). SD5065B Technical manual. BREEAM Communities Assessor Manual Development Planning Application Stage BRE Global Ltd.

Briguglio, L., Cordina, G. et al. (2009). Economic Vulnerability and Resilience: concepts and measurements. Oxford Development Studies, 37 (3), 229-247.

Bussemey Buhe, C. and Achard, G. (1997). Développement d'une méthode de conception environnementale des bâtiments prenant en compte l'environnement de proximité. Tesis, Université de Savoie, 163 p.

Caeiro, S.; Ramos, T. B. et al. (2012). Procedures and criteria to develop and evaluate household sustainable consumption indicators. Journal of Cleaner Production, 27, 72-91.
Casbee, F. U. D. (2007). Technical Manual 2007. Institute for Building Environment and Energy Conservation (IBEC).

Castells, M. and Hall, P. (1996). Tecnópolis del mundo: la formación de los complejos industriales del siglo xxI. Espiral, Estudios sobre Estado y Sociedad, 2 (6).

Chiu, R. L. H. (2003). 12 Social sustainability, sustainable development and housing development. The experience of Hong Kong". In R. Forrest \& J. Lee (Eds.), Housing and social change: East-west perspectives (pp. 221239). USA: Routledge.

Clark, G. (2007). Evolution of the global sustainable consumption and production policy and the United Nations Environment Programme's (UNEP) supporting activities. Journal of Cleaner Production, 15 (6), 492-498.

Clark, W. C. and Dickson, N. M. (2003). Sustainability science: the emerging research program. Proceedings of the National Academy of Sciences, 100(14), 8059.

Clichevsky, N., ECLAC [United Nations Economic Commision] - CEPAL et al. (2000). Informalidad y segregación urbana en América Latina: una aproximación. Naciones Unidas, Comisión Económica para América Latina y el Caribe, División de Medio Ambiente y Asentamientos Humanos.

Cohelo, P.; Mascarenhas, A. et al. (2010). A framework for regional sustainability assessment: developing indicators for a Portuguese region. Sustainable Development, 18 (4), 211-219.

Cohen, M.; Brown, H. et al. (2010). Individual consumption and systemic societal transformation: introduction to the special issue. Sustainability: Science, Practice, \& Policy, 6(2), 6-12.

Conte, E. and Monno, V. (2012). Beyond the buildingcentric approach: A vision for an integrated evaluation of sustainable buildings. Environmental Impact Assessment Review, 34, 31-40.

Coyle, S. and Duany, A. (2011). Sustainable and Resilient Communities: A Comprehensive Action Plan for Towns, Cities, and Regions. Hoboken, N.J.: Wiley.

Crabtree, L. (2005). Sustainable housing development in urban Australia: Exploring obstacles to and opportunities for ecocity efforts. Australian Geographer, 36 (3), 333-350.

Curran, A.; Williams, I. D. et al. (2007). Management of household bulky waste in England. Resources, conservation and recycling, 51 (1), 78-92.

Daniel, D. and Ortmann, J. (2011). Disambiguating Resilience. Geoinformatik, 117-125.

Davidson, R. (1997). An Urban Earthquake Disaster Risk Index. Stanford: The John A. Blume Earthquake Engineering Center, Department of Civil Engineering, Stanford University. Report.
Davoudi, S. and Layard, A. (2001). Sustainable development and planning: an overview. Planning for a Sustainable Future, 7-17.

Druckman, A. and Jackson, T. (2008). Household energy consumption in the UK: A highly geographically and socio-economically disaggregated model. Energy Policy, 36 (8), 3177-3192.

Du Plessis, C. and Cole, R. J. (2011). Motivating change: shifting the paradigm. Building Research \& Information, 39 (5), 436-449.

Engel-Yan, J.; Kennedy, C. et al. (2005). Toward sustainable neighbourhoods: the need to consider infrastructure interactions. Canadian Journal of Civil Engineering, 32 (1), 45-57.

Foladori, G. (2005). Advances and limits of social sustainability as an envolving concept. Canadian Journal of Development Studies/Revue canadienne d'études du développement, 26 (3), 501-510.

Folke, C. (2006). Resilience: The emergence of a perspective for social-ecological systems analyses. Global Environmental Change, 16 (3), 253-267.

Folke, C.; Carpenter, S. et al. (2002). Resilience and sustainable development: building adaptive capacity in a world of transformations. AMBIO: A Journal of the Human Environment, 31 (5), 437-440.

Gallopin, G. C. (2006). Linkages between vulnerability, resilience, and adaptive capacity. Global Environmental Change, 16 (3), 293-303.

Gamboa H. J. D.; Rosillo Pena, M E.; Herrera Caceres, C. A.; López Bernal, O.; Iglesias García, V. (2011). Confort ambiental en vivienda de interés social en Cali. Cali: Programa Editorial Universidad del Valle.

Giménez, G. (2000). Territorio, cultura e identidades. La región sociocultural. En Rosales R. (Coord.). Globalización y regiones en México (19-53). México: UNAM.

Girardet, H. (2004). Cities, people, planet. West Sussex: Wiley-Academy.

Givoni, B. (1998). Climate considerations in building and urban design. New York: International Thomson Publishing.

Godschalk, D. R. (2004). Land use planning challenges: coping with conflicts in visions of sustainable development and livable communities. Journal of the American Planning Association, 70 (1), 5-13.

Haapio, A. (2011). Towards sustainable urban communities. Environmental Impact Assessment Review, 32, 165-169.

Hallegatte, S. (2009). Strategies to adapt to an uncertain climate change. Global Environmental Change, 19 (2), 240-247.

Hardoy, J. and Romero Lankao, P. (2011, May). Latin American cities and climate change: challenges and options to mitigation and adaptation responses. Current Opinion in Environmental Sustainability, 3 (3), 158-163. 
Harguindéguy, J. and Arias, S. A. (2009). All that glitters is not gold, the misuse of the ecodristrict's label in Spain. Publicación del Centro de Estudios Políticos y Constitucionales.

Ipcc, C. C. (2007). The Physical Science Basis. Contribution of Working Group I to the Fourth Assessment Report of the Intergovernmental Panel on Climate Change. Cambridge, United Kingdom and New York: Cambridge University Press.

Kappes, M.; Papathoma-Köhle, M. et al. (2012). Assessing physical vulnerability for multi-hazards using an indicator-based methodology. Applied Geography, 32 (2), 577-590.

Kennedy, C.; Pincetl, S. et al. (2011). The study of urban metabolism and its applications to urban planning and design. Environmental Pollution. 1965-1973.

Kerkhof, A. C.; Nonhebel, S. et al. (2009). Relating the environmental impact of consumption to household expenditures: An inputoutput analysis. Ecological Economics, 68 (4), 1160-1170.

Klein, J.; Fontan, J. et al. (2003). Mundialización, acción colectiva e iniciativa local en la reconversión de Montreal. EURE, 29, 69-88 (Santiago).

Kuntsi-Reunanen, E. (2007). A comparison of Latin American energy-related $\mathrm{CO}_{2}$ emissions from 1970 to 2001. Energy Policy, 35 (1), 586-596

Lazzeri, Y. and Moustier, E. (2008). Le développement durable: du concept à la mesure. Paris: Editions L'Harmattan.

Leed, F. N. D. (2009). The U.S. Green Building Council, Inc.

Lehman, S. (2010). The principles of green urbanism: Transforming the city for sustainability. Routledge.

Lempert, R. J.; Groves, D. G. et al. (2006). A general, analytic method for generating robust strategies and narrative scenarios. Management Science, 52 (4), 514.

$\mathrm{Li}, \mathrm{H}$. (2003). Management of coastal megacities-a new challenge in the 21st century. Marine Policy, 27 (4), 333-337.

Lopez Valencia, A. P. (2011). Construcción de una metodología para el análisis de la sustentabilidad en un territorio industrial. Bogotá: Maestría en Urbanismo, Universidad Nacional de Colombia.

López Bernal, O. y Camelo, A. (2008). La sustentabilidad urbana: una aproximación a la gestión ambiental en la ciudad. Cali: Programa Editorial Universidad del Valle.

Maclaren, V. (1996). Developing indicators of urban sustainability: A focus on the Canadian experience. Toronto: ICURR Press.

Marston, S. A. (2005). World regions in global context: peoples, places, and environments. N.J.: Pearson Prentice Hall.

Mateus, R. and Bragança, L. (2011). Sustainability assessment and rating of Buildings: Developing the methodology SBToolPT-H. Building and Environment.
Mcgill, R. (2001). Urban Management Checklist1. Cities, 18 (5), 347-354.

Mcgranahan, G. (2003). Urban Health \& Development: a practical manual for use in developing countries. Bulletin of the World Health Organization, 80 (3), 256-256.

Mcgranahan, G. and Satterthwaite, D. (2011). Better Health for the Uncounted Urban Masses. Scientific American, 305 (3), 62-62.

Mitlin, D. (2000). Towards more pro-poor local governments in urban areas. Environment and Urbanization, 12 (1), 3-11.

Mostafavi, M. and Doherty, G. (2011). Ecological Urbanism. Urban Design (118), 41.

Nelson, D. R.; Adger, W. N. et al. (2007). Adaptation to environmental change: contributions of a resilience framework. Annu. Rev. Environ. Resour., 32, 395-419.

Olazábal, M.; García, G. et al. (2008). Urban system metabolism analysis: An approach for the definition of urban strategic actions. ConAccount, 376.

Oswald, F.; Baccini, P. et al. (2003). Netzstadt: designing the urban. Birkhauser Architecture. Boston, Berlin: Birkhäuser, Basel.

Papathoma-Köle, M.; Neuhäuser, B. et al. (2007). Elements at risk as a framework for assessing the vulnerability of communities to landslides.

Pelling, M. (1999). The political ecology of flood hazard in urban Guyana. Geoforum, 30 (3), 249-261.

Pesci, R. (2000). La pedagogía de la cultura ambiental: del Titanic al velero. La complejidad. Mexico: Siglo XXI Editores.

Reyos, J. (2009). Community-driven Disaster Intervention: Experiences of the Homeless People's Federation in the Philippines. HPFP. PACSII and IIED.

Ritchie, A. and Thomas, R. (2008). Sustainable urban design: An environmental approach. Recherche, 67, 2.

Rivera-Arriaga, E. (2005). Assessing foreign aid efforts for coastal management in Latin America and the Caribbean regions. Ocean \& coastal management, 48 (9-10), 693-720.

Romero Lankao, P. (2007). Are we missing the point? Environment and Urbanization, 19 (1), 159.

Rudin, D. and Falk, N. (1999). Building the 21st century home. The Sustainable Urban Neighbourhood. Architectural Press.

Ryan, R. L. (2011). The social landscape of planning: Integrating social and perceptual research with spatial planning information. Landscape and Urban Planning. doi:10.1016/j.landurbplan.2011.01.015.

Sachs, I. (1999). Social sustainability and whole development: exploring the dimensions of sustainable development. Sustainability and Social Sciences. London: Zed Books.

Satterthwaite, D. (2009). The implications of population growth and urbanization for climate change. Environment and Urbanization, 21 (2), 545-567.

Satterthwaite, D. et al. (2007). Adapting to climate change in urban areas: the possibilities and constraints in low-and middle-income nations. London: International Institute for Environment and Development.

Seyfang, G. (2009). The new economics of sustainable consumption. N. Y.: Palgrave MacMillan.

Solecki, W.; Leichenko, R. et al. (2011). Climate change adaptation strategies and disaster risk reduction in cities: connections, contentions, and synergies. Current Opinion in Environmental Sustainability.

Tol, R. S. J. and Yohe, G. W. (2007). The weakest link hypothesis for adaptive capacity: an empirical test. Global Environmental Change, 17 (2), 218-227.

Tukker, A.; Cohen, M. J. et al. (2010). Sustainable consumption and production. Journal of Industrial Ecology, 14 (1), 1-3.

Turner, I. (2010). Vulnerability and resilience: Coalescing or paralleling approaches for sustainability science? Global Environmental Change, 20 (4), 570-576.

United Nations (1993). Agenda 21: Programme of Action for Sustainable Development: Rio Declaration on Environment and Development: Statement of Forest Principles: the Final Text of Agreements Negotiated by Governments at the United Nations Conference on Environment and Development (UNCED), 3-14 June 1992, Rio de Janeiro, Brazil, United Nations, UNCED.

Un-Habitat (2009). Planning Sustainable Cities: Global Report on Human Settlements. London: Earthscan.

Un-Habitat (2008). State of the World's Cities: 2008/2009: Harmonious Cities. Earthscan/ James \& James.

Vallance, S.; Perkins, H. C. et al. (2011). What is social sustainability? A clarification of concepts. Geoforum. ScienceDirect. Article in Press. www.elsevier.com/locate/geoforum.

Verdaguer Viana-Cárdenas, C. (2000). De la sostenibilidad a los ecobarrios. Documentación Social. Revista de estudios sociales y sociología aplicada (119), 59-78.

Verdaguer Viana-Cárdenas, C. (2010). De los ecobarrios a las ecociudades: una formulación sintética de la sostenibilidad urbana. Papeles de relaciones ecosociales y cambio global (111), 77-86.

Wisner, B.; Blaikie, P. et al. (1994). At risk: natural hazards, people's vulnerability, and disasters. Framework, 4, 37-48. 
A Los artículos postulados deben corresponder a las categorías universalmente aceptadas como producto de investigación, ser originales e inéditos y sus contenidos responder a criterios de precisión, claridad y brevedad.

Como punto de referencia se pueden tomar las tipologías y definiciones del Índice Bibliográfico Nacional, Publindex, para los artículos tipo 1, 2 y 3 que se describen la continuación:

1) Artículo de investigación científica y tecnológica: documento que presenta, de manera detallada, los resultados originales de proyectos terminados de investigación. La estructura generalmente utilizada contiene cuatro apartes importantes: introducción, metodología, resultados y conclusiones.

2) Artículo de reflexión: documento que presenta resultados de investigación terminada desde una perspectiva analítica, interpretativa o crítica del autor, sobre un tema específico, recurriendo fuentes originales.

3) Artículo de revisión: documento resultado de una investigación terminada donde se analizan, sistematizan e integran los resultados de investigaciones publicadas o no publicadas, sobre un campo en ciencia o tecnología, con el fin de dar cuenta de los avances y las tendencias de desarrollo. Se caracteriza por presentar una cuidadosa revisión bibliográfica de por lo menos 50 referencias.

También se pueden presentar otro tipo de documentos diferentes a los anteriormente descritos como pueden ser: artículo corto, reporte de caso, revisión de tema, documento resultado de la revisión crítica de la literatura sobre un tema en particular, cartas al editor, traducción, documento de reflexión no derivado de investigación, reseña bibliográfica así como proyectos de arquitectura o urbanismo, entre otros.

(A) INSTRUCCIONES PARA POSTULAR ARTÍCULOS

Presentar el artículo mediante comunicación escrita dirigida al Editor de la Revista de Arquitectura en soporte digital y una copia impresa (si es local), adjuntando hoja de vida del autor (diligenciar el formato RevArq FP01 Hoja de Vida*). En la comunicación escrita el autor debe expresar, que conoce y acepta la política editorial de la Revista de Arquitectura, que el artículo no está postulado para publicación simultáneamente en otras revistas u órganos editoriales y que cede todos los derechos de reproducción y distribución del artículo (RevArq FP05 Carta de originalidad*).

Los artículos deben tener en cuenta las siguientes recomendaciones:

- En la primera página del documento se debe incluir

TíTULO: en español e inglés y no exceder 15 palabras.

SUBTíTULO: opcional, complementa el título o indica las principales subdivisiones del texto.

DATOS DEL AUTOR O AUTORES: nombres y apellidos completos, filiación institucional. Como nota al pie: formación académica, experiencia profesional e investigativa, publicaciones representativas y correo electrónico o dirección postal. El orden de los autores debe guardar relación con el aporte que cada uno hizo al trabajo.

DESCRIPCIÓN DEL PROYECTO DE INVESTIGACIÓN: en la introducción describir brevemente el marco investigativo del cual es producto el artículo y diligenciar el formato (RevArq FP02 Info Proyectos de Investigación*).

RESUMEN: debe ser analítico, se redacta en un solo párrafo, da cuenta del tema, el objetivo, los puntos centrales y las conclusiones, no debe exceder las 150 palabras y se presenta español e inglés (Abstract).

PALABRAS CLAVE: cinco palabras o grupo de palabras, ordenadas alfabéticamente y que no se encuentren en el título o subtítulo, deben presentarse español e inglés (Key words), estas sirven para clasificar temáticamente al artículo. Se recomienda emplear principalmente palabras definidas en el tesauro de la Unesco http:// databases.unesco.org/thessp/ o en el tesauro de Arte \& Arquitectura@ www.aatespanol.cl

- La segunda página y siguientes deben tener en cuenta estas recomendaciones:
El cuerpo del artículo generalmente se divide en: Introducción, Metodología, Desarrollo, Resultados y Discusión, y finalmente Conclusiones, luego se presentan las Referencias bibliográficas, Tablas, Leyendas de las Figuras y Anexos.

TEXTO: las páginas deben venir numeradas, a interlineado doble en letra Arial de 12 puntos, la extensión de los artículos debe estar alrededor de 5.000 palabras (20 páginas, incluyendo gráficos, tablas, etc.) y se debe seguir el estilo vigente y recomendado en el Manual para Publicación de la Asociación Americana de Psicología (APA). (Para mayor información http://www. apastyle.org/).

CITAS Y NOTAS AL PIE: las notas aclaratorias o notas al pie no deben exceder más de cinco líneas o 40 palabras, de lo contrario estas deben ser incorporadas al texto general. Cuando se realicen citas estas pueden ser cortas (con menos de 40 palabras), se incorporan al texto y pueden ser: textuales (se encierran entre dobles comillas), parafraseo o resumen (se escriben en sus propias palabras dentro del texto); cita textual extensa (mayor de 40 palabras) debe ser dispuesta en un renglón y un bloque independiente con sangrías y omitiendo las comillas, no olvidar en ningún caso la referencia del autor (Apellido, año, p. 00).

REFERENCIAS: como modelo para la construcción de referencias, se emplea el siguiente:

\section{Libro}

Autor -Apellidos-, A.A. -Nombres- (año de la publicación). Titulo de la obra (Edición). Ciudad: Editorial.

Capítulo de un libro

Autor, A.A., y Autor, B.B. (Año de la publicación). Título del capítulo. En A.A. Editor y B.B. Editor (eds.), Título del libro (páginas del capítulo). Ciudad: Editorial.

\section{Publicación seriada (Revista)}

Autor, A.A., Autor, B.B., y Autor, C.C. (Año de la publicación, incluya el mes y día de la publicación para publicaciones diarias, semanales o mensuales). Título del artículo. Título de la revista, diario, semanario, Volumen, (Número), páginas.

Leyes, decretos, resoluciones, etc.

Ley, decreto, resolución, etc., número (Año, incluya el mes y día de la publicación). Título de la ley, decreto, resolución, etc. Título de la publicación oficialmente. Ciudad, País. 


\section{DIRECCIÓN POSTAL}

Avenida Caracas N 46 - 72. Universidad Católica de Colombia. Bogotá D.C.- Colombia

Código postal: 111311

Centro de Investigaciones de la Facultad de Arquitectura (CIFAR). Sede

El Claustro. Bloque "L", 4 piso, Diag. 46모 No. 15b - 10.

Arq. César Andrés Eligio Triana

Teléfonos: (057-1) 3277300 - 3277333 Ext. 3109 ó 5146

\section{CORREO ELECTRÓNICO:}

revistadearquitectura@ucatolica.edu.co

cifar@ucatolica.edu.co

\section{PÁGINA WEB:}

www.ucatolica.edu.co Vínculo Publicaciones

http://portalweb.ucatolica.edu.co/easyWeb2/arquitectura/pages.

php/menu/319320363/id/2363/content/revista-de-arquitectura/
La Revista de Arquitectura está interesada en establecer canje con publicaciones académicas, profesionales o científicas, del área de Arquitectura y Urbanismo.

Para establecer canje por favor diligenciar y enviar el formato: RevArq FP20 Canjes.

\section{(A) PROCESO DE ARBITRAJE}

Artículo que se encuentra en una revista publicada en Internet

Autor, A.A. y Autor, B.B. (año). Título del artículo. Título de la revista, volumen (número, si se encuentra). Recuperado el día de mes de año, de URL.

SIGLAS: en el caso de emplear siglas en el texto, cuadros, gráficos y/o fotografías, se deben proporcionar las equivalencias completas de cada una de ellas la primera vez que se empleen y encerrarlas entre corchetes [ ]. En el caso de citar personajes reconocidos se deben colocar nombres y/o apellidos completos, nunca emplear abreviaturas.

GráfICOs: las tablas, los gráficos, las figuras, los diagramas, las ilustraciones y las fotografías deben contener el título o leyenda explicativa relacionada con el tema de investigación que no exceda las 15 palabras y la procedencia (autor $y / o$ fuente, año, p. 00). Se deben entregar en medio digital independiente del texto a una resolución mínima de 300 dpi (en cualquiera de los formatos descritos en la sección de fotografía), según la extensión del artículo se deben incluir de 5 a 10 gráficos y su posición dentro del texto.

El autor es el responsable de adquirir los derechos y/o las autorizaciones de reproducción a que haya lugar, para imágenes y/o gráficos tomados de otras fuentes.

FotografíA: pueden ser entregadas en original para ser digitalizadas, de lo contrario se deben digitalizar con una resolución igual o superior a 300 dpi para imágenes a color y 600 para escala de grises. Los formatos de las imágenes pueden ser TIFF, PSD o JPG.

Planimetría: se debe entregar la planimetría original en medio digital en lo posible en formato CAD y sus respectivos archivos de plumas o en PDF. De no ser posible se deben hacer impresiones en tamaño carta con las referencias de los espacios mediante numeración y lista adjunta. Deben poseer escala gráfica, escala numérica, norte, coordenadas y localización. En lo posible no debe tener textos, achurados o tramas.

Para más detalles puede consultar el documento RevArq Parámetros para Autores Descripción en el portal web de la Revista de Arquitectura (www.ucatolica.edu.co).
El Comité Editorial de la Revista de Arquitectura es la instancia que decide la aceptación de los artículos postulados, el editor selecciona y clasifica solo los artículos que cumplan con los requisitos establecidos en las instrucciones para los autores:

Todos los artículos se someterán a un primer dictamen del Comité Editorial teniendo en cuenta:

- Afinidad temática y relevancia del tema.

- Respaldo investigativo.

Después de la preselección se asignan pares evaluadores externos especializados, y se empleará método doble ciego y el formato (RevArq FP10 Evaluación de artículos calidad); del proceso de arbitraje se emitirá alguno de estos conceptos que serán reportados al autor:

- Aceptar el artículo tal como fue entregado.

- Aceptar el artículo con algunas modificaciones: se podrá sugerir la forma más adecuada para una nueva presentación, para lo cual el autor puede o no aceptar las observaciones, de ser así cuenta con quince días hábiles para realizar los ajustes pertinentes.

- Rechazar el artículo: en este caso se entregará al autor un comunicado, evidenciando la razón de la negación de publicación.

El Comité Editorial se reserva el derecho de aceptar o no la publicación del material recibido. También se reserva el derecho de sugerir modificaciones de forma y de someterlo a corrección de estilo.

Cuando un artículo es aceptado para su publicación, los derechos de reproducción y divulgación son de la Universidad Católica de Colombia, lo cual se hará mediante la firma de cesión de derechos (RevArq FP03 Autorización reproducción artículo).

\section{NOTAS ACLARATORIAS:}

Aunque la recepción del material se notificará de inmediato por correo electrónico, los procesos de evaluación, arbitraje, edición y publicación pueden tener un plazo máximo de doce meses.

El editor de la Revista de Arquitectura es el encargado de establecer contacto entre los autores, árbitros, evaluadores y correctores, ya que estos procesos se realizan de manera anónima.

Aunque un artículo sea aceptado podrá quedar aplazado para ser publicado en una próxima edición.
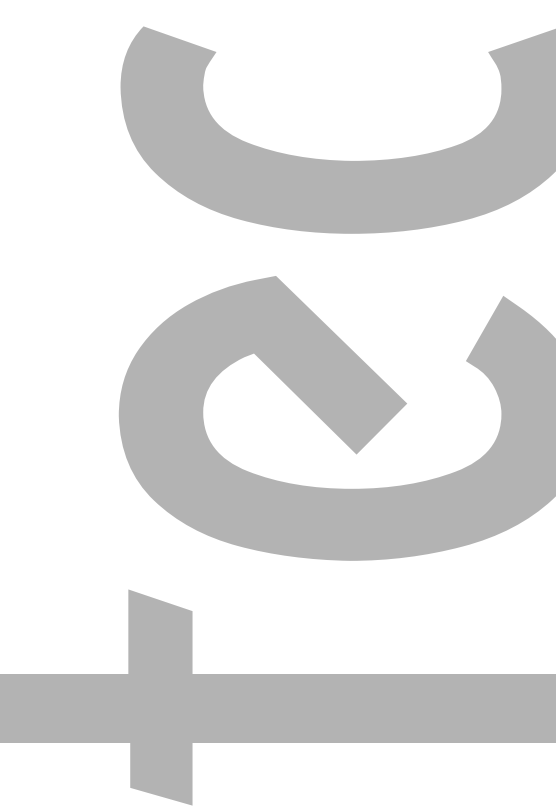

$>$
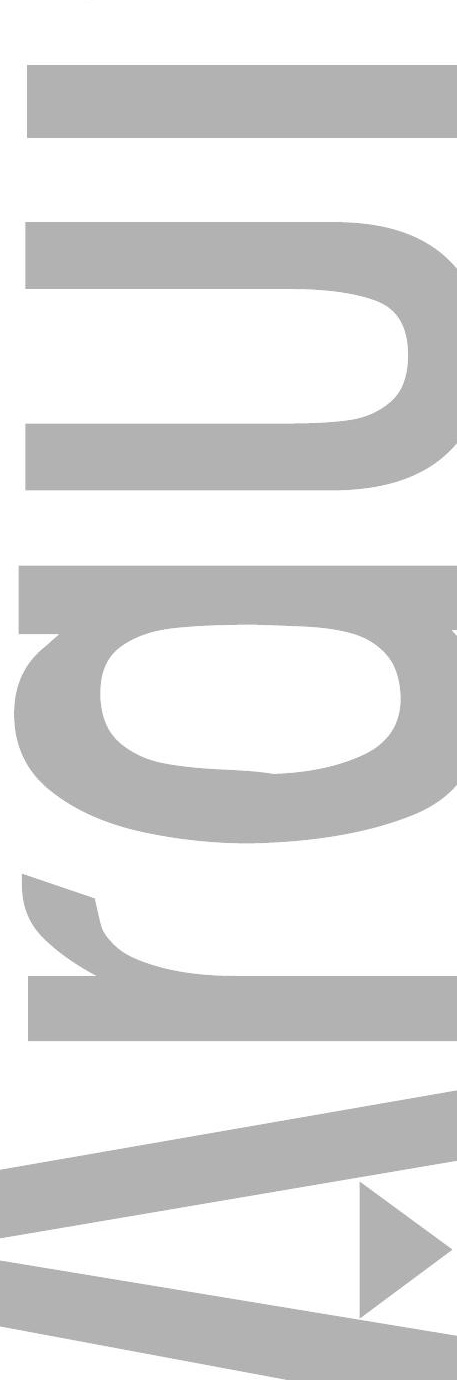
ARQUITECTURA PARTICIPATIVA:

广 LAS FORMAS DE LO ESENCIAL

$\begin{array}{ll}\dot{0} & \text { PARTICIPATIVE ARCHITECTURE: } \\ \dot{\alpha} & \text { FORMS OF THE ESSENTIAL }\end{array}$

WiLLIAM Garcia RAMIREZ

LA CIUDAD MODERNA, LITERALMENTE $\simeq$ HABLANDO

نं O CÓMO LEER LO QUE DICEN LOS ESCRITORES DE FICCIÓN SOBRE

¿ LOS ASENTAMIENTOS

THE MODERN CITY, LITERALLY SPEAKING

OR HOW TO READ WHAT FICTION WRITERS SAY ABOUT URBAN

MAURICIO MUÑOZ

UNA VENTANA PARA VER LA CIUDAD:

유 EL PARK WAY (1944 - 2000)

ن A WINDOW TO SEE THE CITY:

¿ THE PARK WAY (1944-2000)

José OrLando Jaimes Nieto

CARÁCTER, CARÁCTER PÚBLICO, CARACTERES \pm NACIONALES

ن VARIACIONES, PERSISTENCIAS E INTERPRETACIONES EN TORNO A

¿ LA EDILICIA PÚBLICA

CHARACTER, PUBLIC CHARACTER, NATIONAL CHARACTERS

VARIATIONS, PERSISTENCES AND INTERPRETATIONS AROUND THE PUBLIC EDILICIA

DANIELA ALEJANDRA CATTANEO

UN ACERCAMIENTO AL ESPACIO

- ARQUITECTÓNICO

ن AN APPROACH TO THE ARCHITECTURAL SPACE

$\llbracket$ Francisco JaVIER FUENTES Farias

PROPUESTA DE DISEÑO PARA UN TEATRO DE

m I500 ESPECTADORES

i. UNA MIRADA DESDE LOS ORÍGENES DE ESTA TIPOLOGÍA

¿ 2 ARQUITECTÓNICA

DESIGN PROPOSAL FOR A THEATER OF I 500 SPECTATORS

A LOOK FROM THE ORIGINS OF THIS ARCHITECTURAL TYPOLOGY

NORA Alvariño TAPIA

ERnesto FeLIPE SÁNCHEZ

GRANDES IDEAS DEL MUNDO: UNA REALIDAD CONCRETA

jo Tensiones en la Vivienda unifamillar moderna, Osorno, Chile

a GREAT IDEAS IN THE WORLD: A REALITY.

TENSIONS IN THE MOdern SINGLE FAMILY HOUSES, OSORNo, CHILE

Hugo Eduardo Weibel Fernandez

ESTUDIO Y GESTIÓN DE ESTÁNDARES MÍNIMOS

乞n DE FLEXIBILIDAD EN LA VIVIENDA SOCIAL EN

i BOGOTÁ

¿ STUDY OF MINIMUM STANDARDS OF FLEXIBILITY FOR SOCIAL HOUSING IN BOGOTÁ

Rolando Arturo Cubillos GONZALEZ

ESTRATEGIA DIDÁCTICA PARA EL APRENDIZAJE DE - LA HISTORIA Y LA TEORÍA DE LA ARQUITECTURA

نं DIDACTIC STRATEGY FOR THE LEARNING OF THE HISTORY AND THE THEORY OF \& THE ARCHITECTURE

\section{LO MISMO MUY DE OTRA MANERA}

SOBRE LA RELACIÓN ENTRE PROYECTO Y ANÁLIISIS EN EL

(j) APRENDIZAJE DE LA COMPOSICIÓN ARQUITECTÓNICA

THE SAME IN A VERY DIFFERENT WAY

ON THE RELATIONSHIP BETWEEN PROJECT AND ANALYSIS IN ARCHITECTURAL COMPOSITION LEARNING
TIPO, ANÁLISIS Y PROYECTO

a TYPE, ANALYYIS AND PROJECT

¿ें

TRAZO DE LAS BÓVEDAS DE NERVADURAS ○ MEXICANAS DEL SIGLO XVI

Tracing of RibBed VAults of THe I6TH Century In MeXICO

这

CONCEPTUALIZACIÓN DE UN MODELO DE ○ INTERVENCIÓN URBANA SOSTENIBLE

- Ecobarrios en el CONTEXTO LATINOAMERICANO DE RECIENTE

¿

CONCEPTUALIZING A SUSTAINABLE URBAN INTERVENTION MODEL

ECO-NEIGHBORHOODS IN THE RECENTLY INDUSTRIALIZED LATIN-AMERICAN

CONTEXT

AdRIANA PATRICIA LÓPEZ VALENCIA

OSWALDO LÓPEZ BERNAL

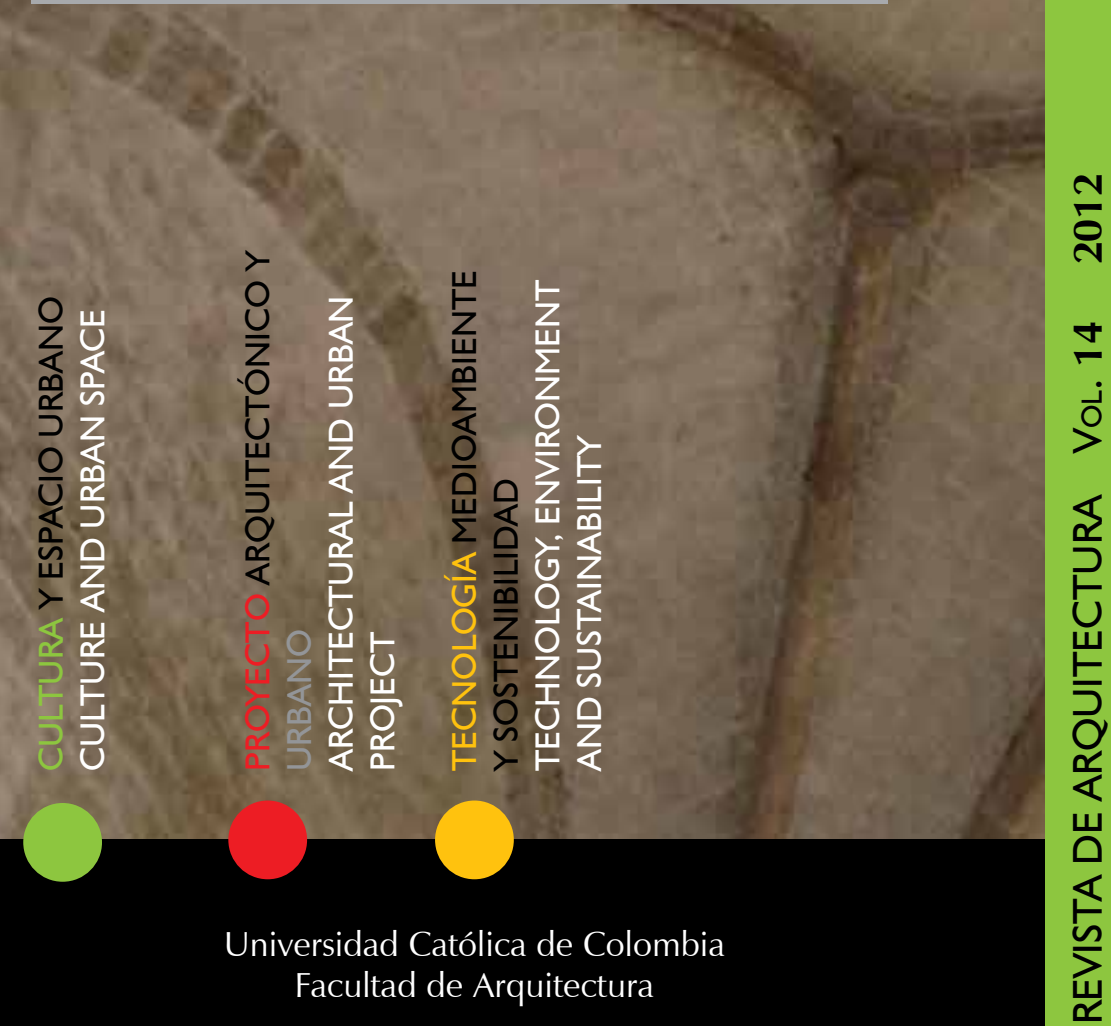

Reacreditación de alta calidad otorgada al Programa

de Arquitectura por el

Ministerio de Educación

Nacional. Resolución 3339 de abril 25 de 2011

Revalidación internacional del Programa de

Arquitectura otorgada por el Royal Institute of British Architects, RIBA

\section{CNA}

RIBA

La Revista de Arquitectura es arbitrada e indexada y está presente en:

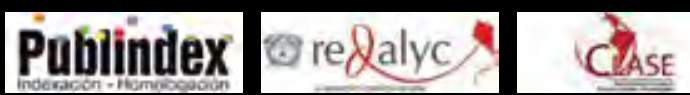

o Dialnet latindex

GiRLA 른 EBSCO

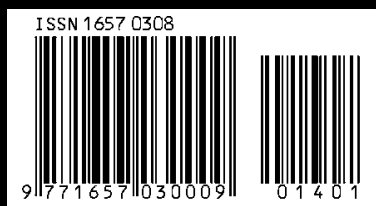

